\title{
Physical Exercise and Catecholamines Response: Benefits and Health Risk - Possible Mechanisms
}

Running title: Physical exercise and catecholamines response

Authors: Joanna Kruk *a, Katarzyna Kotarska b, Basil H. Aboul-Enein c

Affiliations: *aFaculty of Physical Culture and Health, University of Szczecin, Piastów 40b, 70-546 Szczecin, Poland

E-mail: joanna.kruk@usz.edu.pl

ORCID 0000-0002-7551-1927

bFaculty of Physical Culture and Health,

University of Szczecin,

Piastów 40b, 70-546 Szczecin, Poland

E-mail: karzyna.kotarska@usz.edu.pl

ORCID 0000-0001-5679-3466

cFaculty of Public Health \& Policy

London School of Hygiene \& Tropical Medicine,

London WC1H 9SH, UK;

E-mail: basil.aboul-enein@1shtm.ac.uk

ORCID 0000-0002-4957-2136 


\section{Abstract}

Beneficial effect of regular moderate physical exercise (PE) and negative effect of severe exercise and/or overtraining as an activator of the sympathetic nervous system (SNS) have been shown in numerous aspects of human health, including reduced risk of cardiovascular disease, neurological disease, depression, and some types of cancer. Moderate-to-vigorous PE stimulates the SNS activation, releasing catecholamines (CATs) adrenaline, noradrenaline, dopamine that play an important regulatory and modulatory actions by affecting metabolic processes and the immune system. Summary of the dispersed literature in this area and explanation of the biological mechanisms operating between PE-CATs and the immune system would lead to a better understanding of the beneficial and negative effects of PE on health. This overview aimed to: demonstrate representative literature findings on the exercise released CATs levels, major functions performed by these hormones, their interactions withimmune system and their effects on carbohydrate and lipid metabolism. Also, mechanisms of cytotoxic free radicals and reactive oxygen species generation during CATs oxidation, and molecular mechanisms of CATs response to exercise are discussed to demonstrate positive and negative on human health effects. Owing to the large body of the subject literature, we present a representative cross-section of the published studies in this area.

The results show a significant role of CATs in carbohydrate and lipid metabolism, immunity and as generators of reactive oxygen species, depending on PE intensity and duration. Further investigation of the PE-CATs relationship should validate CATs levels to optimize safe intensity and duration of exercise and individualize their prescription, considering CATs to be applied as markers for a dose of exercise. Also, a better understanding of the biological mechanisms is also needed.

Keywords: physical exercise, catecholamines, metabolism, immune system, oxidative stress, mechanisms

\section{Introduction}

Strong epidemiological evidence documents the beneficial and deleterious role of reactive oxygen species (ROS), and nitrogen species (RNS) [1] and the positive effects of regular 
moderate physical activity (PA) on humans' health through its effect on the cellular redox homeostasis and increased resistance to oxidative stress (OS) [2-3]. In contrast, extremely high intensity exercise or endurance exercise not preceded by training can be important mediator of immunosuppression and the cellular macromolecular damage due to increased generation of free radicals, ROS and RNS [4-6].

It is widely accepted that persistent OS is one cause of lifestyle-linked pathological conditions, such as cardiovascular disease (CVD), neurodegenerative disorders, diabetes, cancer, and aging of cells (recently reviewed by $[1,7,8]$ ). Regular moderate PA has the ability to regulate the ROS and RNS concentrations in cells [9]. According to the researchers' statement, mitochondria, xanthine oxidase (XO), NADPH oxidase, neutrophils and other phagocytes, and catecholamines (CATs), such as adrenaline (AD), noradrenaline (NA) are the most frequently postulated shareholders of ROS production during physical exercise $[10,11]$. The most recent evidence confirms an important role of mitochondria as a source of ROS, but simultaneously underlines interplay between mitochondria and other cellular sources of the ROS/RNS release in metabolic processes (including autoxidation and peroxidation of CATs) in the oxidatively damage to biomolecules and their survival, for example, by autophagy and apoptosis [7].

$\mathrm{AD}$ and NA play an important role in an adaptation of the organism at rest and to different shortterm acting stressors, including physical exercise [12], and released at appropriate concentration exhibit antioxidant activity [13]. In contrast, CATs excess release in response to acute physical exercise may induce changes in coagulation, platelet aggregation, and fibrinolysis [14-16]. These hormones play a key role in control growth of some cancers [17]. Following decades of extensive research, there are several inconsistencies regarding the positive and negative influences of PE as generators of ROS/RNS and mediators in CATs secretion. Numerous evidences document the protective effect of regular moderate-to-vigorous PA on human health including some types of cancer growth, recurrence, and human mortality. However, the main question remains unanswered: Why PE only protects against some types of cancer? Also, the dangerous effect of severe PE on CATs secretion and on the immune system, mechanisms of an interconnection between PA, CATs and the immune system are not fully understood. 
With increasing incidence of civilization diseases, obesity and changes in humans' PA linked with dynamic development of technique and health related behavior, the current body of knowledge on the association between PA and CATs cellular levels may be important to understand the link between biological mechanisms and civilization disease burden. Therefore, our review demonstrates evidence on primary functions of CATs in the human body, the PE in connection with CATs release, discusses the effect of this relationship on the immune system and metabolic effects, summarizing the dispersed literature in this area. The anti-inflammatory and proinflammatory actions of CATs are also presented, including the possible biological mechanisms for PA induced changes in these stress hormones secretion, their metabolism, participation in generation of free radicals and ROS, and effects on human's health. Due to the large body of the subject literature, we present a representative cross-section of the published findings in this area.

\section{Catecholamines and their functions}

Over the last 25 years there is growing evidence on the ability of the immune system cells express adrenoreceptors (ARs) to produce and release CATs [18]. The term CATs includes a family of biomolecules containing a catechol or 3,4-dihydroxyphenyl core and amine group in their chemical structure. The most abundant and important CATs are dopamine (DA), noradrenaline (NA), and adrenaline (AD). CATs play an important physiological role regulating cardiac stimulation, blood pressure, and metabolic processes, among others $[15,18]$.

\section{Tissue sources of catecholamines}

CATs are synthesized from L-tyrosine of an amino acid present in dietary proteins or from phenylalanine. During biotransformation, L-tyrosine is converted to 3,4dihydroxyphenylalanine (DOPA) by tyrosine hydroxylases, next an enzyme DOPA decarboxylase catalyzes transformation of DOPA to DA. In turn, DA is converted to NA by dopamine $\beta$-hydroxylase, and NA undergoes transformation to AD by phenylethanolamine Nmethyltransferase $[18,19]$. The last two stages of the stress hormones transformation and release are named in the subject literature as a part of the "fight-or-flight response" [20]. 
Two main sources of CATs production are recognized: The neuroendocrine chromaffin cells of the adrenal glands medulla (AD and NA) and the postganglionic fibers of the sympathetic nervous system (SNS) (NA) [12,19]. Stress hormones NA and AD acts as neurotransmitters in the central nervous system (CNS) and in the SNS and as hormones in blood circulation [21]. Over sixty years research on DA synthesis and distribution showed the hormone occurrence in plants, blood, brain, several peripheral organs, and bone marrow [22,23].

\section{Effects of catecholamines on human body}

According to Paravati and Warrington's suggestion, the external stressors, e.g.PE, diet, fasting, psychological responses, temperature activates the hypothalamic-pituitary-adrenal (HPA) axis and SNS, followed by the increased production of glucocorticords in the adrenal cortex and releasing acetylchoine (Ach) which acts as a neurotransmitter [24]. Ach binds to nicotonic receptors of chromaffin cells in the adrenal medulla, which promotes exocytosis of CATsfilled vesicles for driving into the blood. Next, CATs act through binding to $\alpha$ - or $\beta$-adrenergic receptors ( $\alpha$-ARs, $\beta$-ARs respectively), of a class of $G$ protein-coupled receptors occurring on cell membrane surfaces in smooth muscle and adipose tissue. ARs are divided into subtypes: $\alpha^{1}$-AR, $\alpha^{2}$-AR or $\beta^{1}$-AR, $\beta^{2}$-AR, $\beta^{3}$-AR based on their cellular localization [12,24]. The $\beta^{1}$-AR and $\beta^{2}$-AR form complexes with a $\mathrm{G}$ protein what activates adrenyl cyclase and consequently increases concentration of intracellular cyclic adenozyno-3',5'-monophosphate (cAMP) of the nucleotide which activates protein kinase A (PKA). The last enzyme increases phosphorylation of specific amino acids with adenosine triphosphate (ATP) as a source of phosphate. The cAMP-dependent phosphorylation stimulates free fatty acids (FFAs) oxidation and inhibits their synthesis by acetyl-coenzyme A carboxylase. In turn, $\alpha^{2}$-ARs are coupled with an inhibitory G protein decreasing cAMP levels, while $\alpha^{1}$-ARs are coupled to phosphatidylinositol membrane (the second messenger system), activating a calcium channel and protein kinase $\mathrm{C}$ (PKC) signaling [12,24]. Evidence presents a similar AD activity with $\alpha$-ARs and $\beta$-ARs and a much higher affinity of NA for $\alpha$-ARs than for $\beta$-ARs. The multi-system activity of CATs as neuromodulators in CNS and hormones in blood circulation are summarized in Figure 1. The main activity includes the immune system, the cardiovascular system, respiratory function, and metabolic effects [12,24-27]. 


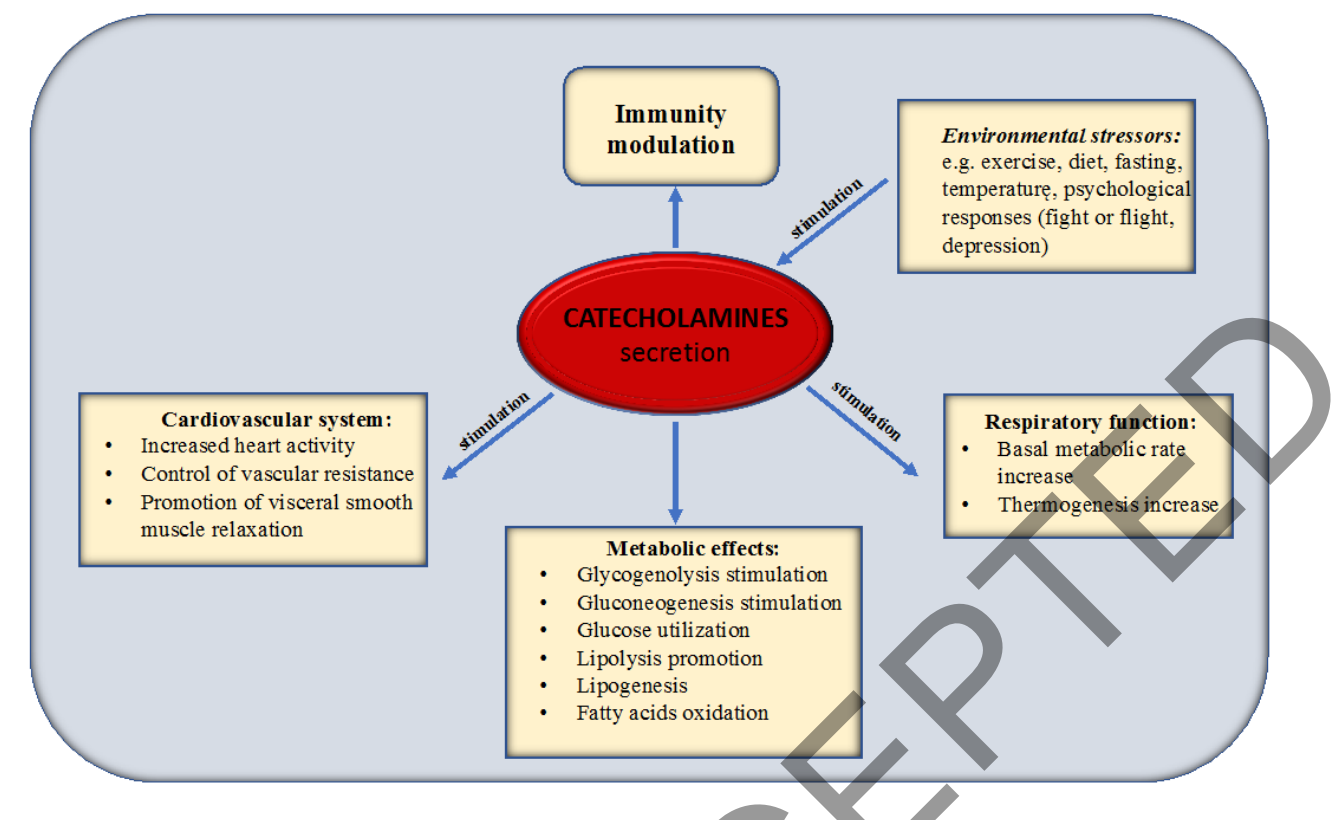

Figure 1. Primary functions performed by catecholamines, based on the literature. AD: Adrenaline, NA: Noradrenaline.

\section{Effect of catecholamines on cardiovascular system and respiratory function}

CATs increase contractility of cardiac muscle and conduction velocity through vasoconstriction using $\alpha$-ARs as well as by vasodilation via $\beta^{2}$-ARs (in skeletal muscle), among other [12]. Although CATs excess followed by external stressor may result in coronary spasm, ultrastructural cell damage and arrythmias. Further, both CATs (AD, NA) exert the stimulatory effect on respiratory function increasing basal metabolic rate followed by nonfacultative thermogenesis, due to increased consumption of molecular oxygen $\left(\mathrm{O}^{2}\right)$. Thus, CATs can exert effect on the $\mathrm{PE}$ duration, playing a key role in the transport of $\mathrm{O}^{2}$ and energetic substrates to active muscle [12].

\section{Effect of catecholamines on carbohydrate and lipid metabolism}

The key role of CATs is their influence on carbohydrate and lipid metabolism as they regulate glycogen breakdown, lipolysis, free fatty acids (FFAs) distribution, and oxidation, lipoprotein 
metabolism, energy expenditure $[12,24,28]$. AD and NA increase blood glucose concentration through glycogen decomposition to glucose in the skeletal muscle using $\beta^{2}$-ARs and through $\alpha^{1}$ - or $\beta^{1}$-ARs in the liver (the process called glycogenolysis). This process affects physical performances in individuals engaged in PE of maximal/supramaximal intensity [12]. Another important process occurring with participation of CATs increasing the blood glucose level is gluconeogenesis, i.e. a synthesis of glucose and glycogen in the liver from other compounds than sugars. Evidence also suggests hyperglycemic effects of CATs. The enhancement of glucagon secretion by $\alpha$-ARs of the pancreas, an inhibition of insulin promotion of glucose uptake by skeletal muscle and the adipose tissue or extinguish of insulin secretion by the pancreas $\alpha$-ARs are examples [12]. Importantly, the controlling insulin secretion is a critical CATs property as insulin lowers glucose concentration in the blood and inhibits a breakdown of the adipose tissue fat [29].

The next important role of CATs is their effect on fatty acid metabolism. This process consists of catabolic pathways that release energy and anabolic processes that form triglycerides, second messengers, phospholipids, hormones, and compounds containing ketone group (ketone bodies) during gluconeogenesis [30] or $\beta$-oxidation, i.e. the process supplying products for energy production by mitochondria [31].

At normal concentration, ketone bodies play an important tuning metabolic role and signaling mediators in response to high carbohydrates level and protect from inflammation. However, a high level of ketone bodies exhibits pro-inflammatory action [32]. CATs, especially AD, are involved in an activation of triacylglycerol lipase in adipose tissue following lipolysis promotion. This process leads to acid hydrolysis of triglyceride to FFAs and glycerol and is regulated by NA, insulin, glucagon, PE, and nutrition [25]. Lipolysis increases FFAs concentration in plasma as a source of the substrates ATP and guanosine-5'-triphosphate in skeletal muscle and other body tissues for energy generation via gluconeogenesis or $\beta$-oxidation. FFAs play a key role during PE, fasting and body weight reduction [12,25]. A dual role of CATs in the effect on lipolysis process is recognized; a stimulation of lipolysis through interaction with $\beta$-ARs and inhibition - through $\alpha^{2}$-ARs, depending on the number of individual subtypes of ARs [12]. Numerous studies have demonstrated differences in CATs influence on lipolysis between 
obese individuals and normal weight individuals, due to decreased activity of triacylglycerol lipase with higher body fatness, a lower number of $\beta$-ARs, and increased activity of $\alpha$-ARs. Adipose tissue, an important endocrine organ regulating many physiological functions, is composed of adipocytes that synthesize fat and stores the excess of energy as fats. White adipose tissue (WAT) stores excess energy as triglycerides and secretes a wide spectrum and quantity of adipokines, including peptide hormones (e.g. insulin, adiponectin, glucagon), steroid hormones, cytokines, and micro ribonucleic acids RNAs (mRNAs) [31,33,34]. This tissue regulates lipid metabolism: Lipogenesis, engages cell proliferation and uptake of FFAs, lipolysis, and FFAs oxidation in mitochondria [35]. Additionally, WAT secretes interleukin-6 (IL-6), tumor necrosis factor-alpha (TNF- $\alpha)$, influences on insulin resistance, and plays an important role as immune organ secreting pro-inflammatory cytokines, being involved in inflammation and induces ROS formation during mitochondrial dysfunction [36].

The best recognized adipokines secreted by adipose tissue are leptin and adiponectin. Leptin exhibits pro-inflammatory, pro-angiogenic, and pro-tumorigenic activities [37]. The leptin receptor expression activates the tyrosine kinase JAK2 (janus kinase 2), transcription factor STAT3 (signal transducer and activator of transcription 3), mitogen-activated protein kinase (MAPK)/extracellular signaling-regulated kinase (ERK1/2) and phosphoinositide 3-kinase (P13) pathways [38]. This shows that leptin plays integrative role in regulation of body energy homeostasis [39]. Evidence has shown that leptin/leptin receptor dysregulation (e.g. genetic polymorphisms, obesity) plays important role in the development several cancers, mainly through JAK/STAT pathway which modified P13/AKT3 and ERK1/2 signaling, expression of anti-apoptic proteins, inflammation through TNF- $\alpha$, IL-6 and also vascular endothelial growth factor (VEGF) and hypoxia-inducible factor-1 alpha (HIF-1 $\alpha$ ) expression [33,40]. In turn, adiponectin starts phosphorylation of adenosine monophosphate (AMP) - activated protein kinase (AMPK) and p38MAPK and increases activity of peroxisome proliferator-activated receptor alpha (PPAR $\alpha)$ ligand [41]. Further, this adipokine stimulates FAs oxidation in skeletal muscle and quenches generation of glucose in the liver. Adiponectin is implicated indirectly in insulin resistance, cell death, and exhibits anti-inflammatory and anti-apoptic activity, among others. It has been suggested that individuals suffering from some types of cancer (liver cancer, 
breast cancer, ovarian cancer) had lowered adiponectin concentrations, while serum levels were strongly increased for leptin [40,42-44].

\section{Interactions of catecholamines with immune system}

The CNS and the immune system cooperate in the assessment of stress and defense against it and in maintaining or restoring the cellular homeostasis $[45,46]$. The sympathetic modulation of immunity is key in the cellular defenses to cope infection and diseases, including autoimmune diseases [45].

Evidence shows two modes of modulation of the immune system by SNS [18,45]. The first involves the direct interaction between CATs (AD and NA) and beta adrenoceptors ( $\beta$-ARs) regulating the immune cells formation, development, proliferation, survival, and circulation [45]. The second mode involves interactions of CATs with endothelial cells, reticular cells, and smooth muscle cells [18]. Evidence suggests these interactions may alter antigen presenting cells, lymphocyte proliferation and redistribution, differentiation, expression of specific receptors, lymphokine-activated killer cells, and immune cell trafficking [2]. The primary function of the $\beta$-ARs subclass is the transmission of information from the extracellular medium to inside the cell. The transport of the information occurs by coupling to the alpha subunit of the stimulatory G protein, stimulation and accumulation of the second messenger cAMP, and activation of PK-A. The last enzyme consisting the catalytic and regulatory subunits plays an important role in metabolism of lipids, glycogen and sugars, and its activity depends on the cellular concentration of cAMP [2]. Induction of VEGF expression by NA and the cAMP/ PK-A pathway by $\beta$-ARs in brown adipocytes has been reported by Moreno-Smith [2].

As previously noted, the duality of physiological role of CATs is reported: The antiinflammatory action and cytotoxic proinflammatory action [18]. The anti-inflammatory effect is the result of CAT action on $\beta^{2}$-ARs and includes both inhibition of T-helper1 proinflammatory cytokines, such as interleukin 12 (IL-12), TNF- $\alpha$, interferon- $\gamma$ (IFN- $\gamma$ ), and induction of T-helper 2, IL-10, and transforming growth factor beta (TGF- $\beta$ ) $[46,47]$.

The proinflammatory immune response of the CATs resulting in activation of $\beta$-ARs on human lymphocytes involves stimulation of the proinflammatory cytokine IL-12 release followed by an increase of IFN- $\gamma$. Other proinflammatory effects may result from activation of $\alpha^{1}$-ARs on 
macrophages or induction of cyclooxygenase-2 (COX-2) [46,48]. Moreover, autoxidation of CATs is accompanied by production of superoxide anion radical $\left(\mathrm{O}^{2 \bullet^{-}}\right)$followed by formation of other ROS/RNS, toxic to cells agents when they are formed in excess [49-51].

The ROS group includes mainly the highest reactive and toxic hydroxyl radical $(\mathrm{HO} \bullet)$, an energetically richer form of molecular oxygen, called singled oxygen $\left({ }^{1} \mathrm{O}^{2}\right)$, and less reactive species, such as $\mathrm{O}^{2 \bullet-}$, hydrogen peroxide $\left(\mathrm{H}^{2} \mathrm{O}^{2}\right)$, hypochlorous acid $(\mathrm{HOCl})$, and ozone $\left(\mathrm{O}^{3}\right)$. The RNS group contains nitric oxide radical $(\mathrm{NO} \bullet)$, nitric dioxide radical $\left(\mathrm{NO}^{2 \bullet}\right)$, and peroxynitrite $\left(\mathrm{ONOO}^{-}\right)$, a species very toxic to cells formed in the reaction of $\mathrm{O}^{2 \bullet}$ with $\mathrm{NO}^{\bullet}$ $[1,52]$. ROS/RNS formed at low/moderate levels play a wide range functions in the redox cellular physiology as secondary messengers, e.g. participate in gene expression or regulation of immune system. In contrast, elevated intracellular concentrations of ROS/RNS can cause oxidative modification of lipids, proteins, and DNA and consequently lead to their function loss. The disrupted cellular homeostasis, i.e. greater imbalance between ROS/RNS generation and their deactivation by endogenous antioxidant systems and/or weakened repair mechanisms of DNA damaged, may result in disruption of redox signaling and biomolecules damage (this redox state is called OS) [1,52-55]. Increased production of ROS/RNS and semiquinone free radicals, owing to oxidative transformation of CATs resulting in damaging modifications of biomolecules including DNA, was observed within neurons [56-62].

Evidence shows CATs are important regulators of tumor angiogenesis $[63,64]$. For example, DA acts on its $\mathrm{D}^{2}$-receptors and suppresses the action of a multifunctional cytokine VEGF which is released in high concentration by cancer cells. This disulfide-bonded dimeric glycoprotein acts on endothelial cells, is involved in the regulation and differentiation of the vascular system and is considered as key mediator of angiogenesis in cancer [65]. However, despite long-lasting research on CATs toxicity, many issues are unsolved. Currently, researchers suggest an activation of $\mathrm{D}^{2}$ dopamine receptor cAMP/PK-A pathway followed by increased expression of nitric oxide synthases (NOSs) is damaging to cells. The enzyme catalyzes NO• production from L-arginine and abnormally high the radical concentration in mammalian cells results in production of $\mathrm{ONOO}^{-}$and carcinogenic $\mathrm{N}$-nitrosamines and further in inflammation, mutagenesis, and neuronal cell death [66]. 
Additionally, excessive accumulation of $\mathrm{O}^{2 \bullet-}$, semiquinones, and $\mathrm{H}^{2} \mathrm{O}^{2}$ also generated during CATs autoxidation may enhance induction of the mitochondrial respiration deficit and OS $[67,68]$. Although, AD and NA may also exhibit opposite action as they may up-regulate the synthesis of many proangiogenic molecules in the mammalian cancer cells, e.g. IL-6, thus stimulate angiogenesis. Consequently, CATs through the $\beta$-adrenergic receptor signaling directly affect malignancy (for exhaustive see Refs [2,69]).

Another important role of CATs is modulation of platelet function which play the key role in the development of cardiovascular disease (CVD) [15,70]. Evidence shows that CATs at higher levels initiate platelets aggregation, secretion, and activate the arachidonate pathway. The role of platelets is known in pathogenesis of vascular damage, such as atherosclerosis and hypertension, and their physiological role is similar to growth factor and inflammatory mediator roles [70-72]. Further, CATs are metabolized by monoamine oxidases (MAO) to aldehydes (e.g. 3,4,-dihydroxyphenylglycolaldehyde in a case of NA metabolism) which are toxic to neurons [59].

\section{Mechanisms of cytotoxic products generation during oxidation of catecholamines}

CATs as phenolic compounds easy undergo oxidation by one-electron pathway involving several toxic products, such as semiquinones, quinones, and ROS, independently on the oxidation promotors (enzymatic, nonenzymatic) [50,73].

Figure 2 shows products of one-electron oxidation of CATs in the presence of molecular oxygen, which have been well experimentally characterized. 


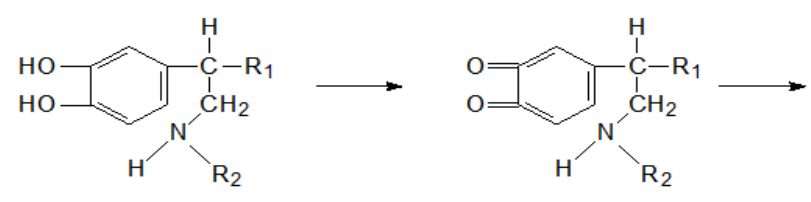

Catecholamine (I)

Catecholamine quinone (II)

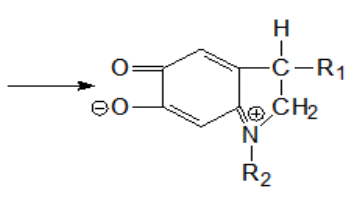

Aminochrome (III)

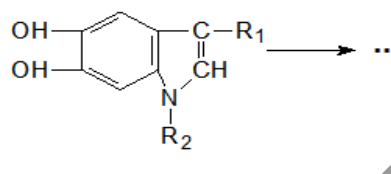

Indole (IV)

Figure 2. Chemical structures of adrenaline $\left(\mathrm{R}^{1}=\mathrm{H}, \mathrm{R}^{2}=\mathrm{H}\right)$, noradrenaline $\left(\mathrm{R}^{1}=\mathrm{OH}, \mathrm{R}^{2}=\mathrm{H}\right)$, and dopamine $\left(\mathrm{R}^{1}=\mathrm{OH}, \mathrm{R}^{2}=\mathrm{CH}^{3}\right)$ and simplified scheme of their oxidation.

The oxidation process involves conversion of CATs to melanines through a few well-defined stages and experimentally identified intermediate products their oxidation. The first step involves CATs ortho-quinones (II) formation which may form stable carbonyl group containing products and bind to thiol (-SH) containing enzymes and form ROS [73].

The next stage of CATs oxidation involves ring closure and the formation of aminochromes (III): adrenochrome, noradrenochrome, and dopachrome of the products of $\mathrm{AD}, \mathrm{NA}, \mathrm{DA}$ oxidation, respectively. The final products of the oxidation process are 5,6-dihydroxyindole compounds (IV) which polymerize into melanines $[50,51,68,74-76]$. There is strong evidence that the process of CATs oxidation in the presence of molecular oxygen and/or transition metal ions $\left(\mathrm{Me} / \mathrm{Me}^{\mathrm{n}+1}\right)$, e.g. $\mathrm{Fe}^{2+} / \mathrm{Fe}^{3+}, \mathrm{Cu}^{+} / \mathrm{Cu}^{2+}$, is accompanied by formation of free radicals $\mathrm{O}^{2 \bullet^{-}}$and semiquinone ( $\left.\mathrm{SQ}^{\bullet}\right)$ as follows [77]:

$$
\mathrm{CAT}+\mathrm{HO}^{-} \rightarrow \mathrm{CAT}^{-}+\mathrm{H}^{2} \mathrm{O}(1)
$$




$$
\begin{aligned}
& \mathrm{CAT}^{-}+\mathrm{O}^{2} \rightarrow \mathrm{CAT}+\mathrm{O}^{2 \bullet-}(2) \\
& 2 \mathrm{O}^{2 \bullet-}+2 \mathrm{H}^{+} \rightarrow \mathrm{H}^{2} \mathrm{O}^{2}+\mathrm{O}^{2}(3) \\
& \mathrm{CAT}+\mathrm{O}^{2 \bullet-}+\mathrm{H}^{+} \rightarrow \mathrm{SQ} \bullet+\mathrm{H}^{2} \mathrm{O}^{2}(4)
\end{aligned}
$$

where $\mathrm{CAT}^{-}$is an anionic form of CAT arising by the dissociation of hydroxyl group of its phenolic ring (reaction 1).

Electron transfer from $\mathrm{CAT}^{-}$to the molecular oxygen leads to the $\mathrm{O}^{2 \bullet-}$ formation (reaction 2). Further, the recombination of two $\mathrm{O}^{2 \bullet^{-}}$molecules gives arising $\mathrm{H}^{2} \mathrm{O}^{2}$ (reaction 3). Elevated $\mathrm{H}^{2} \mathrm{O}^{2}$ level in tissues accelerates formation of aminochromes (III), indoles (IV) and their polymerization to melanines [74]. Another important process in ROS production during CATs conversion involves the redox cycling reactions of ortho-hydroquinones to the highly toxic for cells ortho-semiquinone free radicals and $\mathrm{HO}^{\bullet}$ with participation of the transition metal ions. Also, the formation of the metal ion-CAT complexes plays an important role in oneelectron reduction of aminochromes to their semiquinone radical forms similar to the reduction of aminochromes catalyzed by the nicotinamide adenine dinucleotide (NADH) -cytochrome $\mathrm{P}-450$ reductase complex [58]. In the presence of molecular oxygen $\left(\mathrm{O}^{2}\right)$, the semiquinone forms of CATs and aminochromes consist efficient source of $\mathrm{O}^{2 \bullet-}$ :

$$
\mathrm{SQ} \bullet+\mathrm{O}^{2} \rightarrow \mathrm{Q}+\mathrm{O}^{2 \bullet-}+\mathrm{H}^{+}(5)
$$

where $\mathrm{SQ}^{\bullet}$ is the semiquinone free radical of CAT/aminochrome, and $\mathrm{Q}$ means their quinone forms.

Another important reaction generating free radical species, such as $\mathrm{HO}^{\bullet}$ in the cellular environment are the Fenton-like reaction and the Haber-Weiss reaction, respectively [53,78]:

$$
\begin{aligned}
& \mathrm{Me}^{\mathrm{n}}+\mathrm{H}^{2} \mathrm{O}^{2} \rightarrow \mathrm{Me}^{\mathrm{n}+1}+\mathrm{HO} \bullet+\mathrm{OH}^{-}(6) \\
& \mathrm{H}^{2} \mathrm{O}^{2}+\mathrm{O}^{2 \bullet-} \rightarrow \mathrm{HO} \cdot+\mathrm{OH}^{-}+\mathrm{O}^{2}(7)
\end{aligned}
$$

and the catalytic decomposition of $\mathrm{H}^{2} \mathrm{O}^{2}$ by $\mathrm{Fe}^{3+}[79,80]$

$$
\mathrm{Fe}^{3+}+\mathrm{H}^{2} \mathrm{O}^{2} \rightarrow \mathrm{Fe}^{2+}+\mathrm{HOO}^{\bullet}+\mathrm{H}^{+}(8)
$$

The efficacy of these reactions as a source of ROS can be modified by several factors, e.g. $\mathrm{Fe}^{3+}$ ligands. In vitro experiments presented strongly amplified production of ROS by CATs in the Fenton (occurs with $\mathrm{Fe}^{2+}$ oxidation) and the Fenton-like reactions, due to their abilities to form $\mathrm{Fe}^{3+}$ complexes as compounds with 1,2-dihydroxybenzene structure [81]. In the $\mathrm{Fe}^{3+}$ 
ligands, the $\mathrm{Fe}^{3+}$ ion is transformed to the $\mathrm{Fe}^{2+}$ ion, being a main substrate, which reacts with $\mathrm{H}^{2} \mathrm{O}^{2}$ to generate $\mathrm{HO} \bullet$ (reaction 6).

Additionally, the process of CATs oxidation is accompanied by production of biologically active products in electronically excited state, such as ${ }^{1} \mathrm{O}^{2}$, indoles, and carbonyl containing compounds generated during oxidative degradation $[82,83]$. The following hypothetical reactions may be representative for formation of ${ }^{1} \mathrm{O}^{2}[53,82]$ and also $\mathrm{ONOO}^{-}[1]$ :

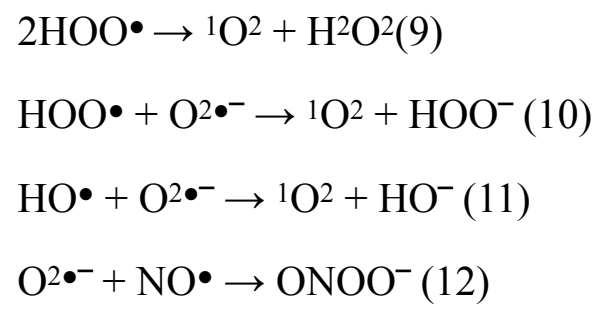

The short-lived $\mathrm{HO} \bullet$ radical and ${ }^{1} \mathrm{O}^{2}$ as well as long-lived semiquinone free radicals and $\mathrm{ONOO}^{-}$exhibit high cytotoxicity and can damage biomolecules. Generally, two mechanisms of CATs cytotoxicity should be considered: Excess ROS production and formation of the covalent bonding between product(s) of CATs oxidation and intracellular proteins. Experimental studies showed CAT-treated animals experienced cardiomyopathy due to free radical production and promotion of lipid peroxidation $[60,84]$. The particular role in CATs cytotoxicity has been described to peroxidation of membrane phospholipids, resulting in a change in the membrane permeability and intracellular Ca ions overload.

\section{Physical activity and catecholamines response}

$\mathrm{PE}$ increases ROS/RNS concentrations, involving disorders in cellular homeostasis [85]. To restore homeostasis, the organism must rapidly respond, and CATs are the first line of response $[12,17,86,87]$. The body of evidence shows CATs concentration may by elevated even 20 -fold after acute exercise compared with their levels at rest [12]. Many factors have been reported to influence the exercise/CAT release association, such as type of exercise (dynamic or static), its intensity and duration (the main factors), training (aerobic, anaerobic), body mass index (BMI), sex, individual's metabolic rate, recovery, age, health status, emotional state, and diet [12,26,87-94].

Table 1 shows the representative data for CATs release during physical exercise. Independently on type of exercise performed, ergometer cycling [26,90,91,95-98], half-marathon run [21], 
SAGI training [99], or treadmill [100], weightlifting [94], a statistically significant increases in plasma CATs concentration were detected, the magnitude of which was dependent on exercise type (intensity, dynamic or static, duration), sex, training, BMI, and health status. The highest magnitude increases in $\mathrm{AD}$ (7 \# 102\% and 3 \# 103\%) and NA (13 \# 102\% and 2 \# $103 \%$ ) released were measured in a professional cyclist group with and without bronchospasm, respectively, performing triangular stress tests [98]. Also, high magnitude increases (3.5-fold, 7fold) in post-exercise plasma of CATs metabolites after half-marathon runs of vigorous intensity $\left(\mathrm{VO}^{2} \max 75-85 \%\right)$ vs the rest were reported by Danese [21]. In turn, Shah et al. [90] observed rapid increases in CATs release above the ventilatory threshold, positively correlated with exercise stages of increased power. This finding may be important in therapy of patients with cardiomyopathy providing information about beneficial dose of PE for individual patients. Similarly, Zouchal et als.' review demonstrated a significant increase in CATs levels for physical effort intensities higher than the maximal aerobic power [12]. Statistically significant increases in blood CATs concentration dependent on the PE type, intensity, and duration were also demonstrated by others $[93,98]$. Henderson et al. [26] observed significantly greater increases in post-exercise concentration of AD and NA in men and women (higher in men) during both moderate and vigorous intensities of exercise. However, vigorous exercise required 2-times shorter duration time than exercise of moderate intensity to reach the same level of CATs, and the magnitudes of increase were found to be higher for NA than for AD. Also, earlier study by Kjaer et al. [89] noticed the plasma NA grows faster than those of AD, which could be detected even during low intensity exercise.

Exercise intensity and duration are the most powerful factors influencing the CATs secretion in response to exercise [12]. The increased CATs levels in plasma with exercise intensity are especially important above lactate threshold, i.e. the point which athletes reach effort, on an average in a range of 50-80\% of their VO2max, and lactate begins to accumulate in the body. Evidence indicated a large quantitative changes of CATs levels with exercise intensity, due to the level of training, duration of exercise, and muscular mass engaged in exercise. Although the increase of CATs release with exercise intensity is well documented, the secretory mechanisms are yet not well recognized. The duration of exercise is another important agent 
increasing the CATs levels for submaximal dynamic exercise. For VO2 = constants, the NA level continuously increases until individual's exhaustion independently on the submaximal exercise intensity. Moreover, there is evidence suggesting that increases of AD and NA concentrations occur even at low intensity exercise with the right exercise duration [12].

Earlier studies reviewed by Zouchal et al. [12] showed a higher AD secretion in endurance trained individuals (both aerobic and anaerobic types) than in untrained individuals. The effect of aerobic training on the CATs response was observed in endurance trained men, but not in women. In the response to exercise of high intensity, the post-exercise concentration of $\mathrm{AD}$ was higher compared to that in non-trained men [12]. In turn, studies on CATs response to exercise in individuals involved in anaerobic training (sprint and/or resistance training) showed mixed results, although cross-sectional studies reported statistically significant higher concentrations of secreted $\mathrm{AD}$ in the sprint-trained men than in those untrained or in the endurance trained men [12]. Trained individuals may benefit from the higher physical performance with regard to a higher CATs concentration as oxygen and fuel carriers.

There is speculation, but not clear consensus on a higher level of CATs release during static, e.g. weight-lifting exercise (keeps only muscles moving) than dynamic exercise, e.g. steady running (keeps muscles and joints moving) [12,101] and positively correlated neurohormones concentrations with individuals' training [12]. Increases of CATs concentrations in plasma were detected during dynamic and static exercise. Experimental studies reported the distinct impact of extensive static and dynamic exercises on some cytokines levels in cytoplasm. Dynamic exercise strongly increased IL-6 and IL-8 concentration in trained athletes, while static exercise increased only IL-15 levels [102]. This may suggest the possibility a higher adrenal response to SNS activity. The effect of physical training on CATs response to exercise was demonstrated in numerous studies $[12,87,89,94]$ more frequently in men than women (see Table $1)$.

In turn, high-intensity resistance exercise overtraining was shown to decrease $\mathrm{B}^{2}$-AR sensitivity, muscular force and decrease in training specific power [94]. This finding indicates SNS plays a basic role in the maintenance of homeostasis in the rest and in response to PE (see Seals and Esler for review [103]). 
Further, the posture of individuals for exercise both at rest and during exercise also exerts effect on the CATs exertion. The hormones concentrations in a vertical position were reported to be significantly higher than those in a sitting or lying position [12]. Evidence suggests that CATs response to exercise can be higher in men compared to women and is dependent on individual types of employed physical training programs.

As reviewed by Zouchal et al., the response of CATs to exercise was significantly higher in men engaged in endurance and sprint-training than in women [12]. These differences were not seen in untrained individuals. The exact reason for the sex difference is suggested to result from the important role of CATs in the transport of oxygen and substrates for energy release in muscles during physical effort. Data show fat oxidation as a source of energy prevails in women, and carbohydrate oxidation in men [104]. The type of energy generation source is determined by the growth hormone and sex steroids interactions [105]. CATs exert their significant effect on physical performance during exercise at $\mathrm{VO}^{2}$ max and at $>\mathrm{VO}^{2}$ max (supermaximal) oxygen demand via regulation of muscular glycogenolysis and hepatic glycogenolysis [12]. Evidence shows women deplete less glycogen than men during PE, thus they can experience a greater benefit in the blood glucose control $[96,106]$. The sex differences have not been well established; it remains to be confirmed with further studies [107].

An important factor determining CATs secretion during exercise is body weight. As seen in Table 1, Jabbour et al. [97] found BMI and body fat were negatively correlated with plasma CATs release. Similar conclusions were reported by others [108] addressing this relationship. The authors maintain low CAT release may indicate reduced SNS power in obese individuals which, in turn, may affect ARs sensitivity in adipose tissue, followed by lipolysis reduction and increased fat storing.

Findings from experimental studies show the SNS activity increases with age targeting gut and skeletal muscle. With age, the AD secretion is reduced, and NA concentration is increased [103]. These changes in CATs levels are hypothesized to result from the increased SNS activity with advanced age and/or activation of a physiological connection between the SNS and the adrenal medulla [12]. Also, health status was a factor influencing CATs release, as 
demonstrated by Dethlefsen et al. [95]. The authors observed significantly higher concentrations of post-exercise plasma AD and NA in breast cancer cases as compared with healthy individuals.

Other potential factors influencing CAT secretion during exercise include emotions/ personality, psychological stress and nutrition. Emotions and psychological stress often accompany sports competition. Huang et al. reported important effects of these factors on the AD, NA, IL-2, and OS levels during response to PE [109]. As CATs are involved in the regulation of the FFAs release during exercise, it is likely that the fasting or timing of food intake exerts an effect on changes of CATs concentrations. For example, a study by Bo et al. observed a change the $\mathrm{AD} / \mathrm{NA}$ concentrations ratio (higher after the morning meals than the evening meals) at rest in moderate active individuals consuming a high-fat and low-fiber diet [110]. Evidence shows that fasting changes of CATs levels either at rest as and in response to the exercise and a lack of the significant evidence on the effect of different types of diet on CATs response to exercise. For a detailed review on the factors influencing CATs release, see a review of Zouchal et al. [12].

Figure 3 summarizes the factors influencing on the CATs response to PE.

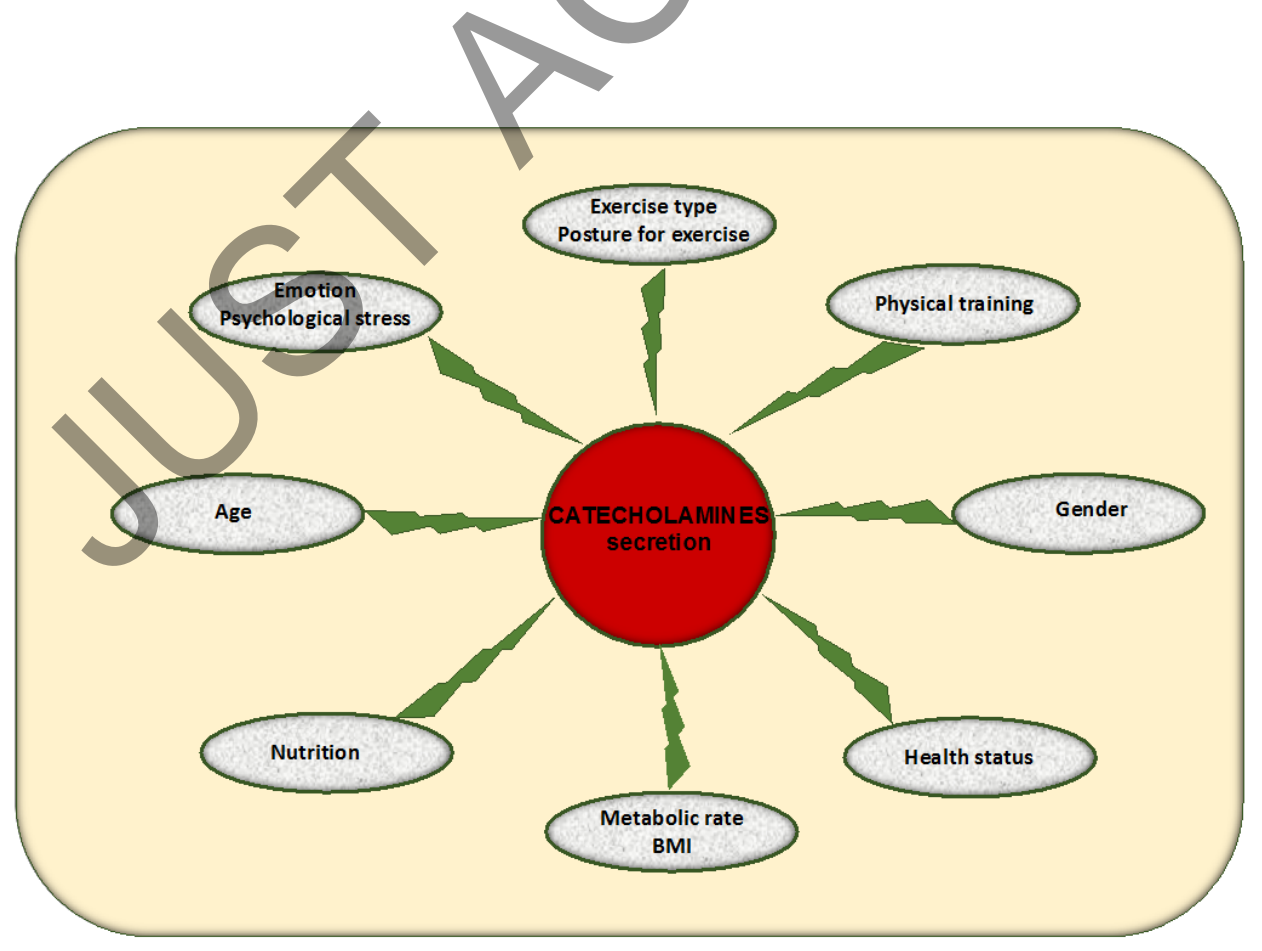


Figure 3. Schematic representation of factors modulating catecholamines secretion in response to physical exercise.

Molecular mechanisms for catecholamines response to physical exercise - evidence for positive and negative effects on human health.

As previously described, PA and its subcategory-PE can exert the beneficial and harmful effects on human health, depending on intensity, frequency, and duration due to exercise effects on the level of circulating lymphocytes, phagocytic cells, NK-cells, and on platelets. According to a World Health Organization statement, PA is an important factor in health and disease, and "insufficient physical activity is one of the leading risk factors for death worldwide" and risk factor for several diseases [111]. Health benefits are the exercise domain of moderateto-vigorous intensity that reduces body weight and fat mass, effects on body composition, well-being, the cardiovascular system, immune functions, and reduces risk of several cancers and depression [3,4,112-119]. For example, the strength of preventive effects of PA for colorectum cancer has been established as "convincing", for postmenopausal breast cancer and endometrial cancer as "probable", for lung, adenocarcinoma, squamous cell carcinoma, liver, and premenopausal cancers as "limited suggestive" [120]. PA may influence cancer progression by a reduction of insulin resistance and its circulating concentrations, decrease of IGF-1 levels, an increase of adiponectin concentrations, regulation of glycolysis and FAs metabolism and ROS generation, enhancement of antioxidant repair mechanisms, and regulation of cancer vasculature [121].

Dependently on concentration of CATs, released during exercise beneficial and negative effects of exercise on human health should be distinguished (Fig. 4). 


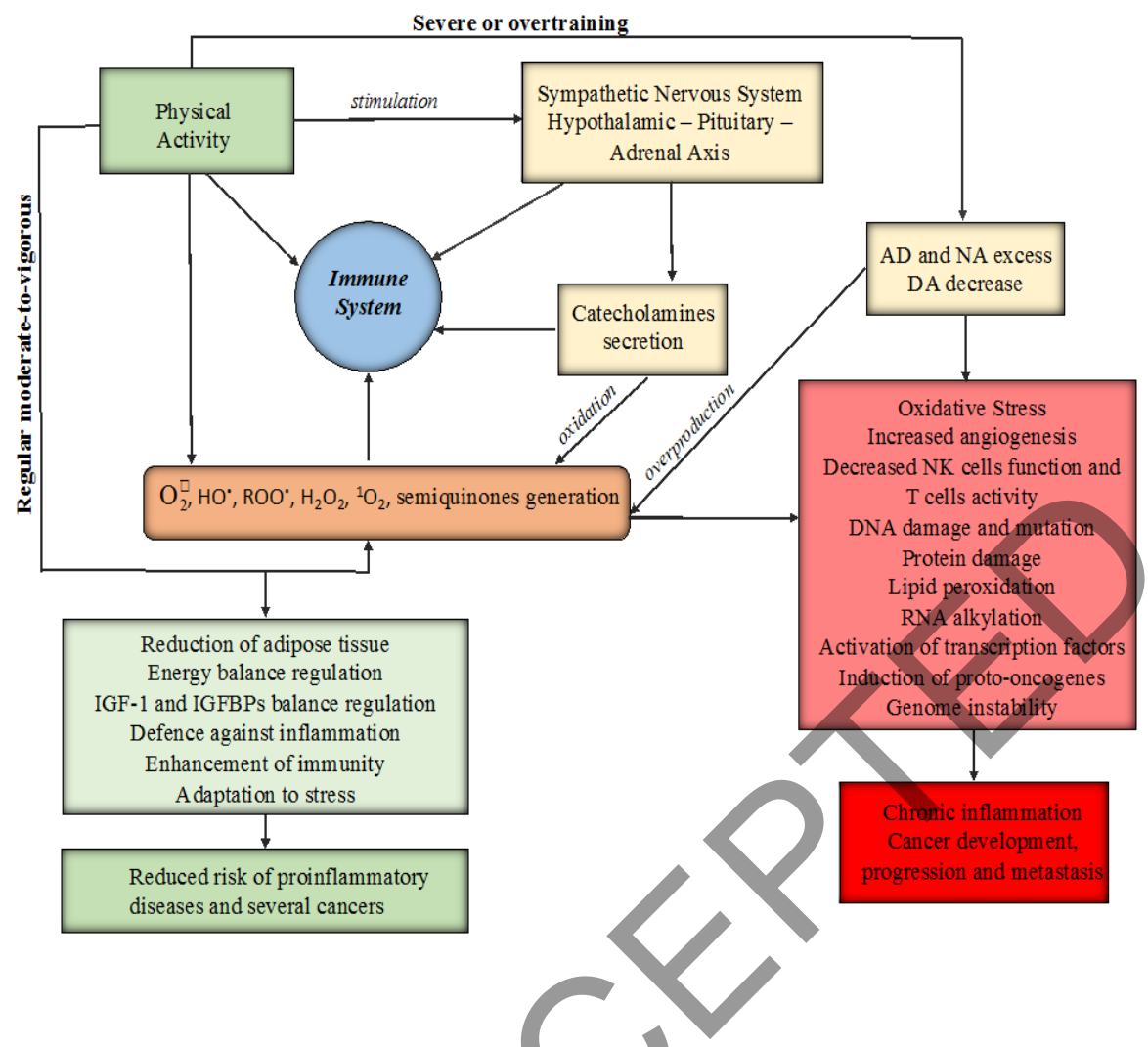

Figure 4. Schematic overview of the physical exercise - catecholamines interaction in prevention against diseases and in chronic inflammation and cancer, based on the literature. IGF-1: Insulin-like growth factor, IGFBPs: Insulin-like growth factor binding proteins.

AD; Adrenaline, NA; noradrenaline, DA; dopamine.

Several mechanisms of the protective effect for PE against cancer has been hypothesized, such as reduction of visceral adipose tissue, increased secretion of myokines by the skeletal muscle, changes in metabolic and sex hormones circulation, reduction of Toll-like receptors (TLRs) on monocytes and macrophages, reduction of inflammation by decrease of proinflammatory adipokines secretion, and enhancement of the immune system function [4,95,122-124].

Reduction of adipose tissue depends on exercise intensity. In individuals involved in moderate-to-high intensity exercise, significantly increased adiponectin concentration and decreased leptin and glucose concentrations were observed [38]. However, data from the literature are not yet consolidated, some studies did not confirm that aerobic PA effects the leptin levels, in contrast to extreme high intensity exercise, such as ultramarathons that induces 
a deficit in energy balance [125 ]. This suggests changes in leptin levels may require physical exertion of extreme intensity. A meta-analysis of 3,602 participants from 17 randomized controlled trials by Rao et al. found significant reduction in visceral adipose tissue (known as leptin generator) in exercise trials for an intervention period of $\geq 6$ months, which was correlated with body weight loss $\left(\mathrm{R}^{2}=0.52\right)$ [124].

Additionally, there is evidence that levels of leptin were significantly lower in tumor tissue and all body sites of aerobic exercise training mice with breast cancer compared to control group, whereas adiponectin concentrations were increased in all sites except of the tumor. Also, the tumor growth and weight were decreased in exercising mice [126]. This suggests the prevention against cancer progression.

Regular moderate-to-vigorous exercise decreases secretion of pro-inflammatory adipokines, e.g. IL-6, TNF, C-reactive protein (CRP) of which high levels can increase cancer risk $[8,127]$. In these interactions an important role is owing to CATs, considered as playing regulatory or modulatory action in cells in response to the stress caused e.g. by exercise, restoring the disturbed balance between pro- and anti-oxidative processes [98,128]. Increased levels of CATs are characteristic of moderate-to-vigorous exercise, but not for exercise of low-to-moderate intensity [4].

Under exercise of moderate-to-vigorous intensity increased levels of released CATs, as a consequence of an activation of SNS and HPA axis linked with an activation of adrenocorticotropic hormone (a stimulator of the adrenal glands), play an important role in the metabolic and skeletal muscle functioning. For example, moderate elevated levels of these neurohormones regulate blood pressure and increase insulin sensitivity and are key agents for the microenvironment of peripheral organs and the human organism adaptation $[21,129]$. Mobilization of the lymphocytes and monocytes to blood stream is caused, in a large extent, by CATs and $\beta$-AR signaling $[130,131]$. Evidence showed increased $\beta$-AR sensitivity in cardiac tissue [132] and in adipose tissue after dynamic strength training [133]. The $\alpha$-ARs and $\beta$-ARs are coupled to G-proteins, which are involved in signal transmission from outside stimulators to inside a cell. The receptors can bind the stimulatory G-protein, thus activating the CAMPdependent PK-A system effecting gene expression, migration, and apoptosis of cells [134]. 
In turn, when the adrenergic receptors bind the inhibitory G-protein, they control multiple signaling cascades, including MAPK - the pathway that has been found to be overactivated in the carcinogenic process [134]. Further, AD and NA may regulate the Hippo tumor suppressor signaling pathway which controls mammalian tissue growth via regulation of cell proliferation and apoptosis [95].

$\mathrm{AD}$ and NA values, independent of individual's age, gender and BMI value, cause a rapid and potent mobilization of NK-cells (up to 6-fold increase in blood during 30 min vigorous exercise), T cells, and $\beta$-cells [130]. The higher level of NK-cells remains throughout training up to 3 hours, after that the cells are probably redistributed to peripheral tissues. The NK and $\mathrm{T}$ cells are the most sensitive among monocytes to $\beta^{2}$-AR signaling and play a key role in infection prevention by exercise $[135,136]$. The NK cells mobilization by CATs was reported as protective against several cancer types, due to infiltration in solid tumors. For example, in mice running on wheel, Idorn and Hojman [130] observed a 50-60\% contribution of intertumoral NK cells in reduction of cancer growth. Experimental in vitro studies on mammalian cells showed NK cells can control tumor growth and metastasis and show anti-inflammatory action (for review see Refs $[47,137]$ ). Thus, an increase of a number of NK cells during the PE-CATs interaction may be responsible for lowering inflammation and enhancing the immune system $[3,4,17,18,138]$. Furthermore, moderate-to-vigorous PE enhances the antioxidant defense via up-regulating resistance to $\mathrm{OS}$, owing to the fact that moderate elevated concentrations of $\mathrm{AD}$ and NA increase concentrations of anti-inflammatory cytokine IL-10, interleukin-1-receptor (IL-1RA) and IGF- $\alpha[139,140]$. The beneficial effect of training with moderate intensity for 6 months and 12 months on low-grade inflammation in overweight and/or obese women manifesting as decrease of leptin, resistin, and IL-6 has been confirmed [127]. Moreover, CATs contain two hydroxyl groups and an amine group in their structure, thus they can prevent $\mathrm{Fe}$ - and $\mathrm{Cu}-$ mediated DNA damage by binding metal ions. This antioxidant property of CATs results in shifting these metals oxidation potentials and stabilization $\mathrm{Fe}^{3+}$ over $\mathrm{Fe}^{2+}$ and $\mathrm{Cu}^{2+}$ and $\mathrm{Cu}^{+}$preventing their redox cycling [141] and functioning as the catalysts of lipid oxidation and the substrate for $\mathrm{HO} \bullet$ production (reaction 6) [13]. Thus, the neurohormones may provide a defense against inflammation. Although, CATs can also induce DNA damage 
mobilizing endogenous $\mathrm{Cu}^{2+}$ ions, reducing them to $\mathrm{Cu}^{+}$; the process is accompanied by ROS formation, thus being involved in carcinogenesis, aging and neurodegeneration [142]. Evidence also shows an important role of DA secreted during regular moderate-to-vigorous $\mathrm{PE}$ in cancer prevention [64]. DA, among other immune cell targets, such as macrophage, monocyte, dendritic cells, NK cells, and B lymphocytes, can activate directly functions of resting $\mathrm{T}$ cells or acts by suppression of regulatory $\mathrm{T}$ cells responses, depending on the neurohormone concentration $[143,144]$. This action is considered beneficial for health. For example, experimental studies showed human glioma cell proliferation was suppressed by DA treatment, due to apoptosis and suppression of proinflammatory mechanisms [64]. Furthermore, DA inhibits tumor development, suppressing the pro-angiogenic action of VEGF and MAPK activation $[112,145]$. There is experimental evidence that low-to-moderate aerobic PE has the potential to modify the tumor microenvironment. In viyo study carried out by McCullough et al., using preclinical model prostate cancer, observed a statistically significant two-fold increased tumor blood flow, the increased number of perfused vessels and decreased by $50 \%$ hypoxia in tumors of rats exercised with low-to-moderate intensity [121]. AD using $\beta$-ARs is a mediator of the increased activation of AMPK in adipocytes induced by acute and regular exercise [146]. Activity of acetyl-coenzyme A carboxylase (ACC) Ser79, an enzyme which limits the rate of FFAs synthesis, is suppressed when Ser $^{79}$ is phosphorylated by AMPK. A high level of ACC phosphorylation, mediated by an increase of AMPK activity and $\beta$-AR signaling, contribute to reduction of abdominal fat, increased insulin sensitivity, AMP/ATP ratio, and lipolysis [146]. PE modulates fat metabolism and carbohydrate metabolism (see Figure 4). During exercise of low-to-moderate intensity, rates of lipolysis and FFAs mobilization are increased in men and women (higher in men), and more FFAs are oxidized than stored in plasma [146]. Fat oxidation increases with exercise intensity until intensity reach about $65 \% \mathrm{VO} 2 \mathrm{max}$, after which the fat oxidation is reduced when exercise intensity continues to increase. Contrary, carbohydrate metabolic rate is positively correlated with the exercise intensity increase. Glucose is transported from liver to the muscle, where can be mostly oxidized (70-99\%) together with glucose-1phosphate form when exercise intensity is above 50\% VO2max. The next difference between fat metabolism and carbohydrate metabolism is the fact that fat oxidation increases with the 
exercise duration, whereas carbohydrate oxidation decreases [26,147]. The alterations exerted by moderate-to-high intensity exercise in fat metabolism are less compared to carbohydrate utilization in skeletal muscle and blood glucose removing [26]. Evidence has also shown the increased lipolysis, FAs oxidation, and NA levels for several hours after exercise session cessation [26].

While short-term moderate to high increase of circulating CATs is necessary for organism survive, prolonged increase in the neurohormones levels can also be dangerous, involving pathological changes in the circulatory, the skeletal system, and the immune system as well as metabolic disturbance, due to enhancing OS and inflammation, among others $[15,59,145]$. An increasing number of OS markers, such as decreased glutathione reduced/ glutathione oxidized ratio, catalase activity, erythrocyte malondialdehyde, 8-OHdG, IL-6 cytokine concentrations, and decreased total antioxidant activity have been found after acute or chronic exercise [148-152].

High levels of ROS, proinflammatory cytokines IL- 6 , TNF- $\alpha$, TNF- $\beta$, CRP, and lipid peroxidation products characteristic for inflammation have been reported as associated with carcinogenesis, insulin resistance, CVD, and neurogeneration [116,153-158]. It was identified that TNF- $\alpha$ release from the adipose tissue leads to insulin resistance. Evidence maintains a synergy between obesity-related insulin resistance and development of cancer [154]. In turn, CRP formation is stimulated by IL-6 secreted by adipose tissue [115]. Although TNF- $\alpha$ is known to induce apoptosis and necrosis, this cytokine, similarly as CRP and IL-6 produced at high concentrations, can exert pro-inflammatory actions and are considered to be involved in carcinogenesis $[8,155]$. Additionally, most genes involved in redox homeostasis regulation as well as ROS and PE show “double edged sword activities" [156,157], exhibiting anti- and pro-inflammatory activities depending on their concentration and environment. Experimental studies have shown that exercise, independently on its intensity, increases transiently NK cells, CD8 ${ }^{+}$cells, and T-cells of both type expression $[3,158]$.

There is sufficient evidence that exhaustive and/or high intense PE is accompanied by creation of an immunodepression "open window" during recovery to the basal state, linked with the changes in the number, proliferation and composition of T- and $\beta$-lymphocytes, NK cells activity, and 
neutrophils due to ARs expression by CATs, among others [2,159]. If individuals are engaged in exercise of high intensity and frequency or they are overstrained without sufficient recovery, the risk of illness is increased owing to increased depression of the immune system, and prolonged exposition to infections increases a risk of illness [160,161]. Evidence demonstrates an important role of $\mathrm{AD}$ and $\mathrm{DA}$ concentration during recovery between exercise bouts. For example, Nalbandian et al. [93] studied levels of CATs during and after acute exercise and found plasma $\mathrm{AD}$ and $\mathrm{DA}$ levels were significantly higher during active recovery (low intensity interval exercise) versus passive recovery. The researchers reported that elevated levels of CATs during active recovery may favor lipolysis and oxidative metabolism, and passive recovery may favor glycolysis. Detailed evidence on CAT-induced lipolysis in adipose tissue and skeletal muscle was shown above and widely discussed in a previous review by Jocken and Blaak [162].

A body of evidence shows the crucial role of HPA axis and SNS in cancer initiation, growth, and progression [69]. The carcinogenesis process, i.e. transformation of normal cells in tumor cells, involves "reprogramming of glucose and FAs metabolism" to maintain a rapid cell proliferation and growth $[163,164]$. Tumor cells exhibit high rate of glucose intake forming lactate, ATP and the increased rate of lipogenesis. Cancer cells metabolism differs from normal cells metabolism because glycolysis and lactic acid fermentation are an important source of energy, compensating lower supply of energy generated by oxidative phosphorylation and decreased mitochondrial respiration [165]. Further, FAs catabolism through the mitochondrial long-chain FA oxidation ( $\beta$-oxidation) can support cancer growth and survival $[30,163]$. FAs are important as an energy source, components of cancer cell membranes, and as signaling molecules involved in cellular homeostasis and as modulators the microenvironment for cancer progression [163].

The excess of $\mathrm{AD}$ and NA in the blood stream exerted during exercise of high intensity and extreme duration, can via ARs cellular signaling pathways enhance cancer cell proliferation and modulate cancer cells interaction with their microenvironment, thus promote tumor growth and progression and prevention of metastasis [128]. These hormones can enhance expression of matrix metalloproteinases (MMPs) and VEGF in adipose tissue using $\beta$-ARs on the tumor cells, followed by vacuolization [69]. 
NE was found to increase VEGF synthesis in several myeloma cancer cells, as well as to increase other proangiogenic factors (IL-6, IL-8) formation [63,128,145,166]. In response to chronic stress, the increased levels of AD and NA and depletion of DA secretion were found in ovarian tissues as well as promotion of angiogenesis in ovarian cancer cells compared with nonstresses cells $[143,145]$. CATs may induce cancer cell growth enhancing cancer cells proliferation, effect on an interaction of cancer cells with their environments, and attenuate apoptosis. Evidence indicates stimulation of adenylyl cyclase activity by $\beta$-AR in response to increased levels of CATs and synthesis of cAMP from ATP, of a compound that regulates lipid and sugar metabolism, cell growth and differentiation, gene transcription, and protein expression, followed by PKA activation [167-169]. Further, the $\beta$-AR/cAMP/PKA signaling may induce DNA damage or influencing expression of pro-inflammatory genes through activation of transcription factors $[128,167]$. Evidence has presented that cellular immune response during the carcinogenic process is multidirectional and anti-or proinflammatory activities are possible, depending on the microenvironmental stimuli [170]. Another important mechanism linked with high levels of secreted CATs is the reduction of macrophages and T-helper lymphocytes of cytokine generators (IL-12, TNF- $\alpha$, TNF- $\gamma$ ), reduction of NK cells activity (an effector lymphocytes of the innate immune system controlling several cancer types and limiting their spread) [144,170-173]), and enhanced release of immunosuppressive factors, e.g.: IL-10, IGF- $\alpha$ [171]. Evidence suggests functional duality in the immune response of IL-10 cytokine, i.e. being implicated in tumor growth as well as its ability to fight cancer [172]. Further, NE can stimulate $\alpha$-ARs in the tumor microenvironment through the activation of the P13/Akt/endothelial NOS pathway [173].

A high consumption of molecular oxygen during exhaustive exercise or long-lasting exercises of high intensity increases levels of CATs and rates their oxidation, causes increases of cellular ROS (e.g. $\mathrm{O}^{2 \bullet-}, \mathrm{H}^{2} \mathrm{O}^{2}, \mathrm{HO}^{\bullet}$ ), and leads to depletion of cellular antioxidant defenses and OSrelated diseases $[174,175]$. Increased ROS levels have been detected in almost all cancer types, where they can participate in tumor cell cycle proliferation, progression, apoptosis, and survival [174-178]. For example, $\mathrm{H}^{2} \mathrm{O}^{2}$ can activate MAPK family following by increase in transcription factor activator protein-1 (AP1) expression. Excess of ROS generation results in activation of 
different signaling pathways MAPK (c-Jun-N-terminal kinase, JNK; p38, ERK) and the redox sensitive transcription factors, e.g. nuclear factor erythroid 2-related factor 2 (Nrf2), NF- $\kappa \mathrm{B}$, AP1, HIF-1 $\alpha$, which play a key role in tumorigenesis [123,179-181]. HIF-1 is an agent that regulates many hypoxia-inducible genes being critical for cancer progression and plays a key role in the tumor cells adaptation to hypotoxic conditions [ 121,182]. Hypoxia (low oxygen tension) disturbs the balance between pro- and anti-angiogenic factors' generation what leads to the enhanced and random blood vessel formation. This state is characteristic for $50-60 \%$ locally advanced solid tumors and favors cancer cells survival and the cancer progression, aggressiveness, and metastasis [183]. Hypoxia in tumors is responsible for advanced but dysfunctional vascularization and stimulates intracellular signaling pathways, among them are: HIF, P13/Akt/mTOR, MAPK (ERK), and NF-кB pathways [184]. These signaling pathways participate in cell proliferation, metabolism, survival, migration, apoptosis, and inflammation, and their interactions may enhance or reduce the tumor hypoxia. The promotion of tumor progression by hypoxia occurs through increased expression of transcription factors and genes participating in induction of genomic instability [184]. The new blood vessels formation in cancer tissue is needed for blood flow to supply oxygen and nutrients for its cells. In tumors, oxygen consumption rates are high owing to proliferating cancer cells and infiltrating immune cells $[183,184]$. Further, ROS are important specific second messengers and can change the redox state of glutathione what enable thioredoxin transformation into nucleus and the DNA binding of NF-kB and consequently an activation of genes participating in cancer cells proliferation and angiogenesis. For example, $\mathrm{H}^{2} \mathrm{O}^{2}$ stabilizes HIF-1 $\alpha$, induces formation of angiogenic agents by tumor cells. The decomposition of $\mathrm{H}^{2} \mathrm{O}^{2}$ by the transition metal ions leads to $\mathrm{HO}^{\bullet}$ generation the most reactive oxygen species (reaction 6) which induces lipid peroxidation, structural alteration of DNA, increases DNA mutation and its damage $[1,123,152,185,186]$. Thus, high level of CATs released during chronic heavy training can exhibit a synergistic effect with exercise in activation of ROS signaling pathways in cancer cells. Under OS conditions, excess CATs secretion exerts a direct effect on immune suppression and contributes to the increased ROS formation due to CATs' peroxidation, as was discussed. It is now evident that $75-90 \%$ of human diseases are associated with disorders of the stress system, 
and acute or chronic systemic inflammation contributes to civilization diseases and occurs in several types of cancer $[160,178,187,188]$. Experimental studies support ARs expression in several types of cancer cells, such as breast, ovarian, colon, and prostate cells $[2,128,166]$.

Knowledge of the impact of PE on tumor process and interaction between PE and CATs release and immunity allows to apply exercise as an important medicine in the management of cancer. In this respect a review by Cormie at al. is illustrative [189].

\section{Conclusions}

Over the last two decades, findings have emerged showing the bimodal role of PE and CATs (AD, NA, DA) secreted as well as their complex interaction for the cell and tissue function. This overview presents primary functions performed by CATs, findings on their release during PE as a result of SNS and HPA axis activation, and the association between PE, CATs, and the immune system in exercise. The article also presents findings on the effect of these hormones on carbohydrate and lipid metabolism, discusses mechanisms generating ROS during their oxidation, and the beneficial and dangerous effects on human health. The growing literature in this field provides strong evidence that a transient increase in the level of CATs during moderateto-vigorous exercise is necessary to response for the exercise linked stress and the organism survive. In contrast, the long-lasting large increase in CATs level, occurring during severe exercise and/or overtraining, can involve pathological changes. Human epidemiological and in vitro animals' studies document the important regulatory and modulatory actions of secreted CATs via influence on respiratory function, cardiovascular system, fat and glucose metabolism, and the immune system, depending on the type and dose of exercise and the health status, among other.

Well documented positive attributes of regular moderate-to-vigorous PA, such as reduction of adipose tissue, increase adiponectin level, decrease serum leptin, and glucose concentrations, decreased secretion of proinflammatory adipokines (IL-6, TNF, CRP) and the enhancement of the immune system may originate from secreted CATs and their response to the activation of specific signaling pathway and mobilization of the right amount of NK, T and B-cells.

Alternatively, strong evidence exists that supports CATs undergoing autooxidation and oxidation in the presence of $\mathrm{H}^{2} \mathrm{O}^{2}$ generate $\operatorname{ROS}\left(\mathrm{O}^{2 \bullet-}, \mathrm{HO} \bullet,{ }^{1} \mathrm{O}^{2}\right)$ and toxic for cells intermediate 
products, such as semiquinone free radicals and quinones. Excessive release of CATs during severe repeated exercise can strengthen an activation of ROS signaling, disturb carbohydrate and lipid metabolism, and alter expression of the genes regulating the redox homeostasis. In consequence that may shift healthy positive effect of CATs towards proinflammatory action and tissue injury, including enhanced cancer cell proliferation and cancer cells interaction with microenvironment promoting cancer growth and progression. The biological mechanisms responsible for tissue injury, the role of CATs and ROS in this process, and the PE-CATs immune system mutual relations are complex and need to be clarified. Although there is common agreement on the dual role of PE, CATs, and ROS in cell functioning, an answer on the main question, what is the optimal dose of exercise and an amount secreted CATs to be health preventive considering the "double edged sword" of ROS and the genes regulating redox homeostasis, requires further research. Further studies should also validate the concentrations of CATs to optimize safe PA programs for disease prevention and treatment and consider these neurohormones as markers for a dose of exercise.

\section{CONSENT FOR PUBLICATION}

Not applicable.

\section{CONFLICT OF INTEREST}

The authors report no conflict of interest.

\section{ACKNOWLEDGEMENTS}

The authors would like to express appreciation to Dr. Joshua Bernstein (A.T Still University of Health Sciences) for providing valuable edits to several initial drafts of this paper. 


\section{REFERENCES}

[1]Valko M, Leibfritz D, Moncol J, et al. Free radicals and antioxidants in normal physiological functions and human disease. Int J Biochem Cell Biol. 2007; 39(1):44-84.

[2]Moreno-Smith M, Lutgendorf SK, Sood AK. Impact of stress on cancer metastasis. Future Oncol. 2010;6(12):1863-1881.

[3]Freidenreich DJ, Volek JS. Immune responses to resistance exercise. Exerc Immunol Rev 2012;18:8-41.

[4]Gleeson M, Bishop NC, Stensel DJ, et al. The anti-inflammatory effects of exercise: mechanisms and implications for the prevention and treatment of disease. Nat Rev Immunol. 2011;11(9):607-615.

[5]Neves PRDS, Tenório TRDS, Lins TA, et al. Acute effects of highand low-intensity exercise bouts on leukocyte counts. J Exerc Sci Fit. 2015;13(1):24-28.

[6]Friedenreich CM, Pialoux V, Wang Q, et al. Effects of exercise on markers of oxidative stress: an ancillary analysis of the Alberta Physical Activity and Breast Cancer Prevention Trial. BMJ Open Sport Exerc Med. 2016;2(1):e000171.

[7]Di Meo S, Reed TT, Venditti P, Victor VM. Role of ROS and RNS sources in physiological and pathological conditions. Oxid Med Cell Longev. 2016;2016:1245049.

[8]Halliwell B, Gutteridge JM. The importance of free radicals and catalytic metal ions in human diseases. Mol Aspects Med. 1985;8(2):89-193.

[9]Montaruli A, Patrini P, Roveda E, et al. Physical activity and breast cancer. Sport Sci Health 2012;8:1-13. 
[10]Powers SK, Jackson MJ. Exercise-induced oxidative stress: cellular mechanisms and impact on muscle force production. Physiol Rev 2008;88(4):1243-1276.

[11]Davies KJ, Quintanilha AT, Brooks GA, Packer L. Free radicals and tissue damage produced by exercise.Biochem Biophys Res

Commun. 1982;107(4):1198-1205.

[12]Zouhal H, Jacob C, Delamarche P, Gratas-Delamarche A.

Catecholamines and the effects of exercise, training and gender. Sports Med. 2008;38(5):401-423.

[13]Gülçin I. Antioxidant activity of L-adrenaline: A structure-activity insight. Chem Biol Interact. 2009;179(2-3):71-80.

[14]Womack CJ, Nagelkirk PR, Coughlin AM. Exercise-induced changes in coagulation and fibrinolysis in healthy populations and patients with cardiovascular disease. Sports Med. 2003;33(11):795-807.

[15]Anfossi G, Trovati M. Role of catecholamines in platelet function: pathophysiological and clinical significance. Eur J Clin Invest. 1996;26(5):353-370.

[16]Siess W, Lorenz R, Roth P, Weber PC. Plasma catecholamines, platelet aggregation and associated thromboxane formation after physical exercise, smoking or norepinephrine infusion. Circulation 1982;66(1):44-48.

[17]Pedersen L, Idorn M, Olofsson GH, et al. Voluntary running suppresses tumor growth through epinephrine- and IL-6-dependent NK cell mobilization and redistribution. Cell Metab. 2016;23(3):554562. 
[18]Casentino M, Kustrimovic N, Marino F. Endogenous catecholamines in immune cells: Discovery, functions and clinical potential as therapeutic targets. BrainImmune: Bridging Neuroscience \& Immunology (October 5, 2013). Retrieved April 2, 2019, from http:// brainimmune.

[19]Januszewicz W, Wocial B, Sznajderman M. Guz Chromochłonny. Państwowy Zakład Wydawnictw Lekarskich Warszawa 1981, pp. $9-21$.

[20]Scott E. All about catecholamines in stress response. Fight - or Flight Chemical Messengers. Stress Menagement, Retrived June 16, 2019 from http://verywellmind.com

[21]Danese E, Tarperi C, Salvagno GL, et al. Sympatho-adrenergic activation by endurance exercise: Effect on metanephrines spillover and its role in predicting athlete's performance. Oncotarget. 2018;9(21):15650-15657

[22]Wichers HJ, Visser JF, Huizing HJ, Pras N. Occurrence of L-DOPA and dopamine in plants and cell-cultures of Mucuna pruriens and effects of 2,4-D and $\mathrm{NaCl}$ on these compounds. Plant Cell Tissue and Organ Culture 1993;33(3):259-264.

[23]Björklund A, Dunnett SB.Fifty years of dopamine research. Trends Neurosci. 2007;30(5):185-187.

[24]Paravati S, Warrington SJ. Physiology, Catecholamines. [Updated 2019 May 5]. StatPearls [Internet]. StatPearls Publishing, Treasure Island (FL). Introduction. Retrieved December 2, 2019.

[25]Luo L, Liu M. Adipose tissue in control of metabolism. J Endocrinol. 2016;231(3): R77-R99.

[26]Henderson GC, Fattor JA, Horning MA, et al. Lipolysis and fatty acid metabolism in men and women during the postexercise recovery period. J Physiol. 2007;584(Pt 3):963-981. 
[27]Quisth V, Enoksson S, Blaak E, et al. Major differences in noradrenaline action on lipolysis and blood flow rates in skeletal muscle and adipose tissue in vivo. Diabetologia 2005;48(5):946953.

[28]Masuo K, Lambert GW. Relationships of adrenoceptor polymorphisms with obesity. J Obes. 2011;2011:609485.

[29]Adeyinka A, Kondamudi NP. Hyperosmolar hyperglycemic nonketotic coma (HHNC, hyperosmolar hyperglycemic nonketotic syndrome) In: StatPearls [Internet]. Treasure Island (FL): StatPearls Publishing; 2019 January. Retrieved 8 December 2019 from ncbi.nlm.nih.gov.

[30]Bu SY, Mashek DG. Hepatic long-chain acyl-CoA synthetase 5 mediates fatty acid channeling between anabolic and catabolic pathways. J Lipid Res. 2010;51(11):3270-3280.

[31]Luong Q, Huang J, Lee KY. Deciphering white adipose tissue heterogeneity. Biology (Basel). 2019;8(2):23.

[32]Veech RL, Bradshaw PC, Clarke K, et al. Ketone bodies mimic the life span extending properties of caloric restriction. IUBMB Life. 2017;69(5):305-314.

[33]Choe SS, Huh JY, Hwang IJ, et al. Adipose tissue remodeling: its role in energy metabolism and metabolic disorders. Front Endocrinol (Lausanne) 2016;7:30; doi:10.3389/fendo.2016.00030.

[34]Lee M-W, Lee M, Oh K-J. Adipose Tissue-Derived Signatures for Obesity and Type 2 Diabetes: Adipokines, Batokines and MicroRNAs. J Clin Med. 2019;8:854.

[35]Zhu Q, Glazier BJ, Hinkel BC, et al. Neuroendocrine regulation of energy metabolism involving different types of adipose tissues. Int $\mathbf{J}$ Mol Sci. 2019;20(11):2707.

[36]Kusminski CM, Scherer PE. Mitochondrial dysfunction in white adipose tissue. Trends Endocrinol Metab. 2012;23(9):435-443. 
[37]Candelaria PV, Rampoldi A, Harbuzariu A, et al. Leptin signaling and cancer chemoresistance: Perspectives. World J Clin Oncol. 2017;8(2):106-119.

[38]Nurnazahiah A, Lua PL, Shahril MR. Adiponectin, leptin and objectively measured physical activity in adults: A narrative review. Malays J Med Sci. 2016;23(6):7-24.

[39]Houseknecht KL, Portocarrero CP. Leptin and its receptors: regulators of whole-body energy homeostasis. Domest Anim Endocrinol. 1998;15(6):457-475.

[40]Dutta D, Ghosh S, Pandit K, et al. Leptin and cancer:Pathogenesis and modulation. Indian J Endocrinol Metab. 2012;16(Suppl 3):596-600.

[41]Fang H, Judd RL. Adiponectin regulation and function. Compr Physiol. 2018;18;8(3):1031-1063.

[42]Park J, Morley TS, Kim M, et al. Obesity and cancer--mechanisms underlying tumour progression and recurrence. Nat Rev Endocrinol. $2014 ; 10(8): 455-465$.

[43]Vansaun MN. Molecular pathways: adiponectin and leptin signaling in cancer. Clin Cancer Res. 2013;19(8):1926-1932.

[44]Chen DC, Chung YF, Yeh YT, et al. Serum adiponectin and leptin levels in Taiwanese breast cancer patients. Cancer Lett. 2006;8;237(1):109-114.

[45] Bellinger DL, Millar BA, Perez S, et al. Sympathetic modulation of immunity: relevance to disease. Cell Immunol. 2008;252(1-+2):2756.

[46]Crotty TP. The balance between the pro-inflammatory effect of plasma noradrenaline and the anti-inflammatory effect of neuronal noradrenaline determines the peripheral effects of noradrenaline. Med Hypotheses 2015;85(5):517-29. 
[47]Mandal A, Viswanathan C. Natural killer cells: In health and disease. Hematol Oncol Stem Cell Ther. 2015;8(2):47-55.

[48]Hinojosa AE, Caso JR, García-Bueno B, et al. Dual effects of noradrenaline on astroglial production of chemokines and proinflammatory mediators. J Neuroinflammation. 2013;10:81.

[49]Amin JK, Xiao L, Pimental DR, et al. Reactive oxygen species mediate alpha-adrenergic receptor-stimulated hypertrophy in adult rat ventricular myocytes. J Mol Cell Cardiol. 2001; 33(1):131-139.

[50]Terland O, Almås B, Flatmark T, et al. One-electron oxidation of catecholamines generates free radicals with an in vitro toxicity correlating with their lifetime. Free Radic Biol Med. 2006;41(8):12661271.

[51]Terland O, Flatmark T, Tangerås A, Grønberg M. Dopamine oxidation generates an oxidative stress mediated by dopamine semiquinone and unrelated to reactive oxygen species. J Mol Cell Cardiol. 1997;29(6):1731-1738.

[52]Schieber M, Chandel NS. ROS function in redox signaling and oxidative stress. Curr Biol. 2014;24(10):R453-R462.

[53]Kellogg EW, Fridovich I. Superoxide, hydrogen peroxide, and singlet oxygen in lipid peroxidation by a xanthine oxidase system. J Biol Chem. 1975;250(22):8812-8817.

[54]Kruk J, Aboul-Enein HY. Reactive oxygen and nitrogen species in carcinogenesis: Implications of oxidative stress on the progression and development of several cancer types. Mini Rev Med Chem. 2017;17(11):904-919.

[55]Sies H. Oxidative stress: oxidants and antioxidants. Exp Physiol. 1997;82(2):291-295.

[56]Salim S. Oxidative Stress and the Central Nervous System. J Pharmacol Exp Ther. 2017;360(1):201-205. 
[57]Spencer WA, Jeyabalan J, Kichambre S, et al. Oxidatively generated DNA damage after $\mathrm{Cu}(\mathrm{II})$ catalysis of dopamine and related catecholamine neurotransmitters and neurotoxins: Role of reactive oxygen species. Free Radic Biol Med. 2011;50(1):139-147.

[58]Baez S, Segura-Aguilar J. Formation of reactive oxygen species during one-electron reduction of noradrenochrome catalyzed by NADPH-cytochrome P-450 reductase. Redox Report 1994;1(1):6570.

[59]Chan AS, Ng LW, Poon LS, et al. Dopaminergic and adrenergic toxicities on SK-N-MC human neuroblastoma cells are mediated through $\mathrm{G}$ protein signaling and oxidative stress. Apoptosis 2007;12(1):167-179

[60]Singal PK, Kapur N, Dhillon KS, et al. Role of free radicals in catecholamine-induced cardiomyopathy. Can J Physiol Pharmacol. 1982;60(11):1390-1397.

[61]Costa VM, Carvalho F, Bastos ML, et al. Contribution of catecholamine reactive intermediates and oxidative stress to the pathologic features of heart diseases. Curr Med Chem. 2011;18(15):2272-2314.

[62]Huang CJ, Webb HE, Zourdos MC, Acevedo EO. Cardiovascular reactivity, stress, and physical activity. Front Physiol. 2013;4:314.

[63]Yang EV, Donovan EL, Benson DM, Glaser R. VEGF is differentially regulated in multiple myeloma-derived cell lines by norepinephrine. Brain Behav Immun. 2008;22(3):318-323.

[64]Lan YL, Wang X, Xing JS, et al. Anti-cancer effects of dopamine in human glioma: involvement of mitochondrial apoptotic and antiinflammatory pathways. Oncotarget. 2017;8(51):88488-88500. 
[65]Senger DR, Van de Water L, Brown LF, et al. Vascular permeability factor (VPF, VEGF) in tumor biology. Cancer Metastasis Rev. 1993;12(3-4):303-324.

[66]Marietta M.A. Nitric oxide synthase: Function and mechanism. In: Ayling JE, Nair MG, Baugh CM (eds) Chemistry and Biology of Pteridines and Folates. Advances in Experimental Medicine and Biology, 1993, vol 338. Springer, Boston, MA, pp.281-284.

[67]Arriagada C, Paris I, Sanchez de las Matas MJ, et al. On the neurotoxicity mechanism of leukoaminochrome o-semiquinone radical derived from dopamine oxidation: mitochondria damage, necrosis, and hydroxyl radical formation. Neurobiol Dis. 2004;16(2):468-477.

[68]Asanuma M, Miyazaki I, Ogawa N. Dopamine- or L-DOPA-induced neurotoxicity: the role of dopamine quinone formation and tyrosinase in a model of Parkinson's disease. Neurotox Res. 2003;5(3):165176.

[69]Chakroborty D, Sarkar C, Basu B, et al. Catecholamines regulate tumor angiogenesis. Cancer Res. 2009;69(9):3727-3730.

[70]Arinell K, Blanc S, Welinder KG, et al. Physical inactivity and platelet function in humans and brown bears: A comparative study. Platelets 2018;29(1):87-90.

[71]Heber S, Volf I. Effects of physical (in)activity on platelet function. Biomed Res Int. 2015;2015:165078.

[72]Esler M, Kaye D, Lambert G, et al. Adrenergic nervous system in heart failure.

Am J Cardiol. 1997;80(11A):7L-14L.

[73]Ito S, Yamanaka Y, Ojika M, Wakamatsu K. The metabolic fate of ortho-quinones derived from catecholamine metabolites. Int J Mol Sci. 2016;17(2):164. 
[74]Swan GA. Structure, Chemistry, and Biosynthesis of the Melanins. In: Herz W, Grisebach H., Kirby G.W. (eds) Progress in the Chemistry of Organic Natural Products 1974, vol 31, Springer, Vienna, s.22.

[75]Anderson DG, Mariappan SV, Buettner GR, Doorn JA. Oxidation of 3,4-dihydroxyphenylacetaldehyde, a toxic dopaminergic metabolite, to a semiquinone radical and an ortho-quinone. J Biol Chem. 2011;286(30):26978-26986.

[76]Kim J, Hong H, Heo A, Park W. Indole toxicity inyolves the inhibition of adenosine triphosphate production and protein folding in Pseudomonas putida. FEMS Microbiol Lett. 2013;343(1):89-99.

[77]Misra HP, Fridovich I. The role of superoxide anion in the autoxidation of epinephrine and a simple assay for superoxide dismutase. J Biol Chem. 1972;247(10):3170-3175.

[78]Haber F, Weiss J. The catalytic decomposition of hydrogen peroxide by iron salts. Proc. R. Soc. Ser A. 1934:332-351.

[79]Walling C, Weil T. The ferric ion catalyzed decomposition of hydrogen peroxide in perchloric acid solution. Int J Chem Kinet. 1974;6(4):507-516.

[80]De Laat J, Gallard H. Catalytic decomposition of hydrogen peroxide by Fe(III) in homogeneous aqueous solution: Mechanism and kinetic modeling. Environ Sci Technol. 1999;33(16):2726-2732.

[81]Melin V, Henríquez A, Freer J, et al. Reactivity of catecholaminedriven Fenton reaction and its relationships with iron (III) speciation, Redox Report 2015;20(2):89-96.

[82]Bielski BHJ, Allen AO. Mechanism of the disproportionation of superoxide radicals. J Phys Chem. 1977;81(11):1048-1050. 
[83]Kruk I, Lichszteld K, Michalska T, et al. The formation of singlet oxygen during oxidation of catecholamines as detected by infrared chemiluminescence and spectrophotometric method. Z Naturforsch C. $1989 ; 44(11-12): 895-900$.

[84]Albino Teixeira A, Azevedo I, Branco D, et al. Sympathetic denervation caused by long-term noradrenaline infusions; prevention by desipramine and superoxide dismutase. Br J Pharmacol. 1989;97(1):95-102.

[85]Radak Z, Chung HY, Koltai E, et al. Exercise, oxidative stress and hormesis. Ageing Res Rev. 2008;7(1):34-42.

[86]McMorris T, Hale BJ. Is there an acute exercise-induced physiological/biochemical threshold which triggers increased speed of cognitive functioning? A meta-analytic investigation. J Sport Health Sci. 2015;4(1):4-13.

[87]Rogers PJ, Tyce GM, Weinshilboum RM, et al. Catecholamine metabolic pathways and exercise training. Plasma and urine catecholamines, metabolic enzymes, and chromogranin-A. Circulation 1991;84(6):2346-2356.

[88]Eavier R, Pequignot JM, Desplanches D, et al. Catecholamines and metabolic responses to submaximal exercise in untrained men and women. Eur J Appl Physiol Occup Physiol. 1983;50(3):393-403.

[89]Kjaer M, Christensen NJ, Sonne B, et al. Effect of exercise on epinephrine turnover in trained and untrained male subjects. J Appl Physiol. 1985;59(4):1061-1067.

[90]Shah AB, Bechis MZ, Brown M, et al. Catecholamine response to exercise in patients with non\#obstructive hypertrophic cardiomyopathy. J Physiol. 2019;597(5):1337-1346.

[91]Simeunovic D, Seferovic PM, Ristic AD, et al. Evaluation of oxidative stress markers and catecholamine changes in patients with dilated 
cardiomyopathy before and after cardiopulmonary exercise testing. Hellenic J Cardiol. 2015;56(5):394-401.

[92]Cadegiani FA, Kater CE. Hormonal aspects of overtraining syndrome: a systematic review. BMC Sports Sci Med Rehabil. 2017;9:14.

[93]Nalbandian HM, Radak Z, Takeda M. Effects of active recovery during interval training on plasma catecholamines and insulin. J Sports Med Phys Fitness. 2018;58(6):917-922.

[94]Fry AC, Schilling BK, Weiss LW, Chiu LZ. Beta2-adrenergic receptor downregulation and performance decrements during high-intensity resistance exercise overtraining. J Appl Physiol. (1985) 2006;101(6):1664-1672.

[95]Dethlefsen C, Hansen LS, Lillelund C, et al. Exercise-induced catecholamines activate the hippo tumor suppressor pathway to reduce risks of breast cancer development. Cancer Res. 2017; 77(18): 4894-4904.

[96]Justice TD, Hammer GL, Davey RJ, et al. Effect of antecedent moderate-intensity exercise on the glycemia-increasing effect of a 30-sec maximal sprint: a sex comparison. Physiol Rep. 2015;3(5):e12386.

[97]Jabbour G, Lemoine-Morel S, Casazza GA, et al. Catecholamine response to exercise in obese, overweight, and lean adolescent boys. Med Sci Sports Exerc. 2011;43(3):408-415.

[98]Messan F, Tito A, Gouthon P, et al. Comparison of catecholamine values before and after exercise-induced bronchospasm in professional cyclists. Tanaffos 2017;16(2):136-143.

[99]Wochyński Z, Sobiech K. Impact of special aviation gymnastics instruments training on selected hormones in cadets' blood serum and plasma. Int J Occup Med Environ Health. 2017;30(4):655-664. 
[100]Ipekoğlu G, Sever O, Gönülateş S, et al. Does chronic smoking affect induced-exercise catecholamine release? Int J Appl Exercise Physiol. 2017;6(1):2322-3537.

[101]Kozlowski S, Brzezinska Z, Nazar K, et al. Plasma catecholamines during sustained isometric exercise. Clin Sci Mol Med. 1973;45(6):723-731.

[102]Kapilevich LV, Zakharova AN, Kabachkova AV, et al. Dynamic and static exercises differentially affect plasma cytokine content in elite endurance- and strength-trained athletes and untrained volunteers. Front Physiol. 2017;8:35.

[103]Seals DR, Esler MD. Human ageing and the sympathoadrenal system. J Physiol 2000;528(3):407-417.

[104]Brockman NK, Yardley JE. Sex-related differences in fuel utilization and hormonal response to exercise: implications for individuals with type 1 diabetes. Appl Physiol Nutr Metab. 2018;43(6):541-552.

[105]Fernández-Pérez L, de Mirecki-Garrido M, Guerra B, et al. Sex steroids and growth hormone interactions. Endocrinol Nutr. 2016;63(4):171-180.

[106]Hedrington MS, Davis SN. Sexual dimorphism in glucose and lipid metabolism during fasting, hypoglycemia, and exercise. Front Endocrinol (Lausanne) 2015;6:61.

[107]Wiecek M, Maciejczyk M, Szymura J, Szygula Z. Sex differences in oxidative stress after eccentric and concentric exercise. Redox Rep. 2017;22(6):478-485.

[108]Zouhal H, Lemoine-Morel S, Mathieu ME, et al. Catecholamines and obesity: effects of exercise and training. Sports Med. 2013;43(7):591600. 
[109]Huang C-J, Webb HE, Evans RK, et al. Psychological stress during exercise: immunoendocrine and oxidative responses. Exp Biol Med. 2010;235(12):1498-1504.

[110]Bo S, Broglio F, Settanni F, et al. Effects of meal timing on changes in circulating epinephrine, norepinephrine, and acylated ghrelin concentrations: a pilot study. Nutr Diabetes. 2017;7(12):303.

[111]World Health Organization (WHO). Physical activity 23 February 2018. http//www.who.int, Accessed July 7, 2019.

[112]Swain DP. Moderate or vigorous intensity exercise. which is better for improving aerobic fitness? Prev Cardiol. 2005;8(1):55-58.

[113]Bird SR, Hawley JA. Update on the effects of physical activity on insulin sensitivity in humans. BMJ Open Sport Exerc Med. 2017;2(1):e000143.

[114]Hong S, Dimitrov S, Pruitt C, et al. Benefit of physical fitness against inflammation in obesity: role of beta-adrenergic receptors. Brain Behav Immun. 2014;39:113-120.

[115]Wang A, Qin F, Hedlin H, et al. Physical activity and sedentary behavior in relation to lung cancer incidence and mortality in older women: The Women's Health Initiative. Int J Cancer 2016;139(10):2178-2192.

[116]Fair AM, Montgomery K. Energy balance, physical activity, and cancer risk. Methods Mol Biol. 2009;472:57-88.

[117]Webb HE, Rosalky DA, McAllister MJ, et al. Aerobic fitness impacts sympathoadrenal axis responses to concurrent challenges. Eur J Appl Physiol. 2017;(2):301-313.

[118]Lawler PR, Filion KB, Eisenberg MJ. Efficacy of exercise-based cardiac rehabilitation post-myocardial infarction: a systematic review and meta-analysis of randomized controlled trials. Am Heart J. 2011;162(4):571-584.e2. 
[119]Anzuini F, Battistella A, Izzotti A. Physical activity and cancer prevention: a review of current evidence and biological mechanisms. J Prev Med Hyg. 2011;52(4):174-180.

[120]World Cancer Research Fund \& American Institute for Cancer Research. The CUP Panel's judgements. Summary of conclusion 2018. https:www.wcrf.org.Accessed July 2, 2019.

[121]McCullough DJ, Stabley JN, Siemann DW, et al. Modulation of blood flow, hypoxia, and vascular function in orthotopic prostate tumors during exercise. J Natl Cancer Inst. 2014;106(4):dju036; doi:10.1093/jnci/dju036.

[122]Wekesa A, Harrison M, Watson RW. Physical activity and its mechanistic effects on prostate cancer. Prostate Cancer Prostatic Dis. 2015;18(3):197-207.

[123]Rebillard A, Lefeuvre-Orfila L, Gueritat J, Cillard J. Prostate cancer and physical activity: adaptive response to oxidative stress. Free Radic Biol Med. 2013;60:115-124.

[124]Rao S, Pandey A, Garg S et al. Effect of exercise and pharmacological interventions on visceral adiposity: A systematic review and meta-analysis of long-term randomized controlled trials. Mayo Clin Proc. 2019;94(2):211-224.

[125]Benatti FB, Lancha AH Junior, et al. Leptin and endurance exercise: implications of adiposity and insulin. Rev Bras Med Esporte, Niterói;13(4):263-269.

[126]Amani Shalamzari S, Daneshfar A, Hassanzadeh Sablouei M, et al. The effect of aerobic training on tumor growth, adiponectin, leptin and ghrelin in mice models of breast cancer. Iran Red Crescent Med J. 2018;20(2):e13305.

[127]Gondim OS, de Camargo VT, Gutierrez FA, et al. Benefits of regular exercise on inflammatory and cardiovascular risk 
markers in normal weight, overweight and obese adults. PLoS One 2015;10(10):e0140596.

[128]Tank AW, Wong DL. Peripheral and central effects of circulating catecholamines. Compr Physiol. 2015;5(1):1-15.

[129]Sharma S, Merghani A, Mont L. Exercise and the heart: the good, the bad, and the ugly. Eur Heart J. 2015;36(23):1445-1453.

[130]Idorn M, Hojman P. Exercise-dependent regulation of nk cells in cancer protection. Trends Mol Med. 2016;22(7):565-577.

[131]Byrne CJ, Khurana S, Kumar A, Tai TC. Inflammatory signaling in hypertension: regulation of adrenal catecholamine biosynthesis. Front Endocrinol (Lausanne). 2018;9:343.

[132]Calvert JW, Condit ME, Aragón JP, et al. Exercise protects against myocardial ischemia-reperfusion injury via stimulation of $\beta(3)$ adrenergic receptors and increased nitric oxide signaling: role of nitrite and nitrosothiols. Circ Res. 2011;108(12):1448-1458.

[133]Polak J, Moro C, Klimcakova E, et al. Dynamic strength training improves insulin sensitivity and functional balance between adrenergic alpha $2 \mathrm{~A}$ and beta pathways in subcutaneous adipose tissue of obese subjects. Diabetologia 2005;48(12):2631-2640.

[134]Pullar CE, Isseroff RR. The beta 2-adrenergic receptor activates promigratory and pro-proliferative pathways in dermal fibroblasts via divergent mechanisms. J Cell Sci. 2006;119(Pt 3):592-602.

[135]Graff RM, Kunz HE, Agha NH, et al. $\beta 2$-adrenergic receptor signaling mediates the preferential mobilization of differentiated subsets of CD8+ T-cells, NK-cells and non-classical monocytes in response to acute exercise in humans. Brain Behav Immun. 2018;74:143-153. 
[136]Krüger K, Lechtermann A, Fobker M, et al. Exercise-induced redistribution of $\mathrm{T}$ lymphocytes is regulated by adrenergic mechanisms. Brain Behav Immun. 2008;22(3):324-338.

[137]Campbell KS, Hasegawa J. Natural killer cell biology: an update and future directions. J Allergy Clin Immunol. 2013;132(3):536-544.

[138]Idorn M, Thor Straten P. Exercise and cancer: from "healthy" to "therapeutic"? Cancer Immunol Immunother. 2017;66(5):667-671.

[139]Morillas-Ruiz JM, Hernández-Sánchez P. Oxidative stress and antioxidant defenses induced by physical exercise. In. Basic Principles and Clinical Significance of Oxidative Stress (Thatha Gowder ed.) 2015 fttp://intechopen.com. Retrieved 16 September 2019. doi: $105772 / 61547$.

[140]Calegari L, Nunes RB, Mozzaquattro BB, et al. Exercise training improves the IL-10/TNF- $\alpha$ cytokine balance in the gastrocnemius of rats with heart failure. Braz J Phys Ther. 2018;22(2):154-160.

[141]García CR, Angelé-Martínez C, Wilkes JA, et al. Prevention of ironand copper-mediated DNA damage by catecholamine and amino acid neurotransmitters, L-DOPA, and curcumin: metal binding as a general antioxidant mechanism. Dalton Trans. 2012;41(21):6458-6467.

[142]Rehmani N, Zafar A, Arif H, et al. Copper-mediated DNA damage by the neurotransmitter dopamine and L-DOPA: A pro-oxidant mechanism. Toxicol In Vitro. 2017;40:336-346.

[143]Levite M, Marino F, Cosentino M. Dopamine, T cells and multiple sclerosis (MS). 2017;124(5):525-542.

[144]Kerage D, Sloan EK, Mattarollo SR, McCombe PA. Interaction of neurotransmitters and neurochemicals with lymphocytes. J Neuroimmunol. 2019;332:99-111. 
[145]Moreno-Smith M, Lu C, Shahzad MM, et al. Dopamine blocks stress-mediated ovarian carcinoma growth. Clin Cancer Res. 2011;17(11):3649-3659.

[146]Koh HJ, Hirshman MF, He H, et al. Adrenaline is a critical mediator of acute exercise-induced AMP-activated protein kinase activation in adipocytes. Biochem J. 2007;403(3):473-481.

[147]Jeukendrup AE. Modulation of carbohydrate and fat utilization by diet, exercise and environment. Biochem Soc Trans. 2003;31(Pt 6):1270-1273.

[148]Michailidis Y, Jamurtas AZ, Nikolaidis MG, et al. Sampling time is crucial for measurement of aerobic exercise-induced oxidative stress. Med Sci Sports Exerc. 2007;39(7):1107-1113.

[149]Mrakic-Sposta S, Gussoni M, Moretti S, et al. Effects of mountain ultra-marathon running on ROS produc- tion and oxidative damage by micro-invasive analytic techniques. PLOS ONE. 2015; 10(11):e0141780.

[150]Hadzovic-Dzuvo A, Valjevac A, Lepara O, et al. Oxifative stress status of elite athelets enganged in different sport disciplines. Bosn J Basic Med Sci. 2014;14(2):56-62.

[151]El Abed K, Ammar A, Boukhris O, et al. Independent and Combined Effects of All-Out Sprint and Low-Intensity Continuous exercise on plasma oxidative stress biomarkers in trained judokas. Front Physiol. 2019;10:842; doi:10.3389/fphys.2019.00842.

[152]Kruk J, Aboul-Enein HY, Kładna A, Bowser EJ. Oxidative stress in biological systems and its relation with pathophysiological functions: the effect of physical activity on cellular redox homeostasis, Free Rad Res. 2019;53(5):497-521. 
[153]Benito B, Gay-Jordi G, Serrano-Mollar A, et al. Cardiac

arrhythmogenic remodeling in a rat model of long-term intensive

exercise training. Circulation 2011;123(1):13-22.

[154]Orgel E, Mittelman SD. The links between insulin resistance, diabetes, and cancer. Curr Diab Rep. 2013;13(2):213-222.

[155]Liu YZ, Wang YX, Jiang CL. Inflammation: the common pathway of stress-related diseases. Front Hum Neurosei. 2017;11:316.

[156]Lüscher TF. Sport, exercise, and daily activity: a double-edged sword revisited. Eur Heart J. 2016;37(32):2505-2507.

[157]Udensi UK, Tchounwou PB. Dual effect of oxidative stress on leukemia cancer induction and treatment. J Exp Clin Cancer Res. 2014;33:106.

[158]LaVoy EC, Hussain M, Reed J, et al. T-cell redeployment and intracellular cytokine expression following exercise: effects of exercise intensity and cytomegalovirus infection. Physiol Rep. 2017;5(1):e13070.

[159]Peake JM, Neubauer O, Walsh NP, et al. Recovery of the immune system after exercise. J Appl Physiol. (1985), 2017;122(5):10771087.

[160]Swaab DF, Bao AM, Lucassen PJ. The stress system in the human brain in depression and neurodegeneration. Ageing Res Rev. 2005;4(2):141-194.

[161]Yano H, Kremenik MJ, Uchida M, Oyanagi E. Benefits of post-stress immunosuppression: a viewpoint from exercise immunology. J Phys Fitness Sports Med. 2018;7(3):153-159. 
[162]Jocken JWE, Blaak EE. Catecholamine-induced lipolysis in adipose tissue and skeletal muscle in obesity. Physiol Behav. 2008;94(2):219230.

[163]Koundouros N, Poulogiannis, G. Reprogramming of fatty acid metabolism in cancer. Br J Cancer 2019; doi:10.1038/ s41416-019-0650-z.

[164]Tirado-Vélez JM, Joumady I, Sáez-Benito A, et al. Inhibition of fatty acid metabolism reduces human myeloma cells proliferation. PLOS ONE 2012;7(9):e46484.

[165]Puchalska P, Crawford PA. Multi-dimensional roles of ketone bodies in fuel metabolism, signaling, and therapeutics. Cell Metab. 2017;25(2):262-284.

[166]Shin KJ, Lee YJ, Yang YR, et al. Molecular mechanisms underlying psychological stress and cancer. Curr Pharm Des. 2016;22(16):2389_ 2402.

[167]Jenkins FJ, Van Houten B, Bovbjerg DH. Effects on DNA damage and/or repair processes as biological mechanisms linking psychological stress to cancer risk. J Appl Biobehav Res. 2014;19(1):3-23.

[168]Yan K, Gao LN, Cui YL, et al. The cyclic AMP signaling pathway: Exploring targets for successful drug discovery (Review). Mol Med Rep. 2016;13(5):3715-3723.

[169]Gao MH, Lai MC, Roth DM, et al. Adenylylcyclase increases responsiveness to catecholamine stimulation in transgenic mice. Circulation 1999;99(12):1618-1622.

[170]Ashan R, Mahmud-Al-Rafat A, Sobhani ME, et al. Biomolecular basis of the role of chronic psychological stress hormone "glucocorticoid" in alteration of cellular immunity during cancer. Memo 2013;6:127-136. 
[171]Paul S, Lal G. The molecular mechanism of natural killer cells function and its importance in cancer immunotherapy. Front Immunol. 2017;8:1124.

[172]Kicielińska J, Pajtasz-Pisecka E. The role of IL-10 in the modulation of the immune response in normal conditions and the tumor environment. Post Hig Med Dosw. 2014;68:879-892.

[173]Afrisham R, Paknejad M, Soliemanifar O, et al. The influence of psychological stress on the initiation and progression of diabetes and cancer. Int J Endocrinol Metab. 2019;17(2):e67400.

[174]Azad MB, Chen Y, Gibson SB. Regulation of autophagy by reactive oxygen species (ROS): implications for cancer progression and treatment. Antioxid Redox Signal. 2009;11(4):777-790.

[175]Nambiar VK, Chalappurath DR. Thrombotic tendencies in excess catecholamine states. In: Biogenic Amines in Neurotransmission and Human Disease. 2019; IntechOpen (ed.) doi: 10.5772/ intechopen. 73738 .

[176]Liou GY, Storz P. Reactive oxygen species in cancer. Free Radic Res. 2010;44(5):479-496.

[177]Zonneville J, Safina A, Truskinovsky AM, et al. TGF- $\beta$ signaling promotes tumor vasculature by enhancing the pericyte-endothelium association. BMC Cancer 2018;18(1):670.

[178]Holmes C, Cunningham C, Zotova E, et al. Systemic inflammation and disease progression in Alzheimer disease. Neurology 2009;73(10):768-774.

[179]Barb D, Williams CJ, Neuwirth AK, et al. Adiponectin in relation to malignancies: a review of existing basic research and clinical evidence. Am J Clin Nutr. 2007;86(3):858-866.

[180]Michalakis K, Williams CJ, Mitsiades N. Serum adiponectin concentrations and tissue expression of adiponectin receptors are 
reduced in patients with prostate cancer: a case control study. Cancer Epidemiol Biomarkers Prev. 2007;16(2):308-313.

[181]Angel CZ, Iguacel I, Mullee A, et al. Appetite-regulating hormones - leptin, adiponectin and ghrelin — and the development of prostate cancer: a systematic review and exploratory meta-analysis. Prostate Cancer Prostatic Dis. 2019; doi:10.1038/s41391-019-0154-1.

[182]Huang D, Li T, Li X, et al. HIF-1-mediated suppression of acylCoA dehydrogenases and fatty acid oxidation is critical for cancer progression. Cell Rep. 2014;8(6):1930-1942

[183]Rankin EB, Giaccia AJ. Hypoxic control of metastasis. Science. 2016;352(6282):175-180.

[184]Muz B, de la Puente P, Azab F, et al. The role of hypoxia in cancer progression, angiogenesis, metastasis, and resistance to therapy. Hypoxia (Auck1). 2015;3:83-92.

[185]Cadet J, Wagner JR. DNA base damage by reactive oxygen species, oxidizing agents, and UV radiation. Cold Spring Harb Perspect Biol. 2013;5(2):a012559.

[186]Kruk J,Aboul-Enein BH, Bernstein J, et al. Psychological stress and cellular aging in cancer: A meta-analysis. Oxid Med Cell Longev. 2019; 2019, Article ID 1270397, 23 pages.

[187]Liao Z, Chua D, Tan NS. Reactive oxygen species: a volatile driver of field cancerization and metastasis. Mol Cancer 2019;18(1):65.

[188]Straub RH, Schradin C. Chronic inflammatory systemic diseases: An evolutionary trade-off between acutely beneficial but chronically harmful programs. Evol Med Public Health 2016;2016(1):37-51.

[189]Cormie P, Zopf EM, Zhang X, et al. The impact of exercise on cancer mortality, recurrence, and treatment-related adverse effects. Epidemiol Rev. 2017;Apr 27:1-22. 
Table 1. The effect of physical exercise on plasma catecholamine levels in humans

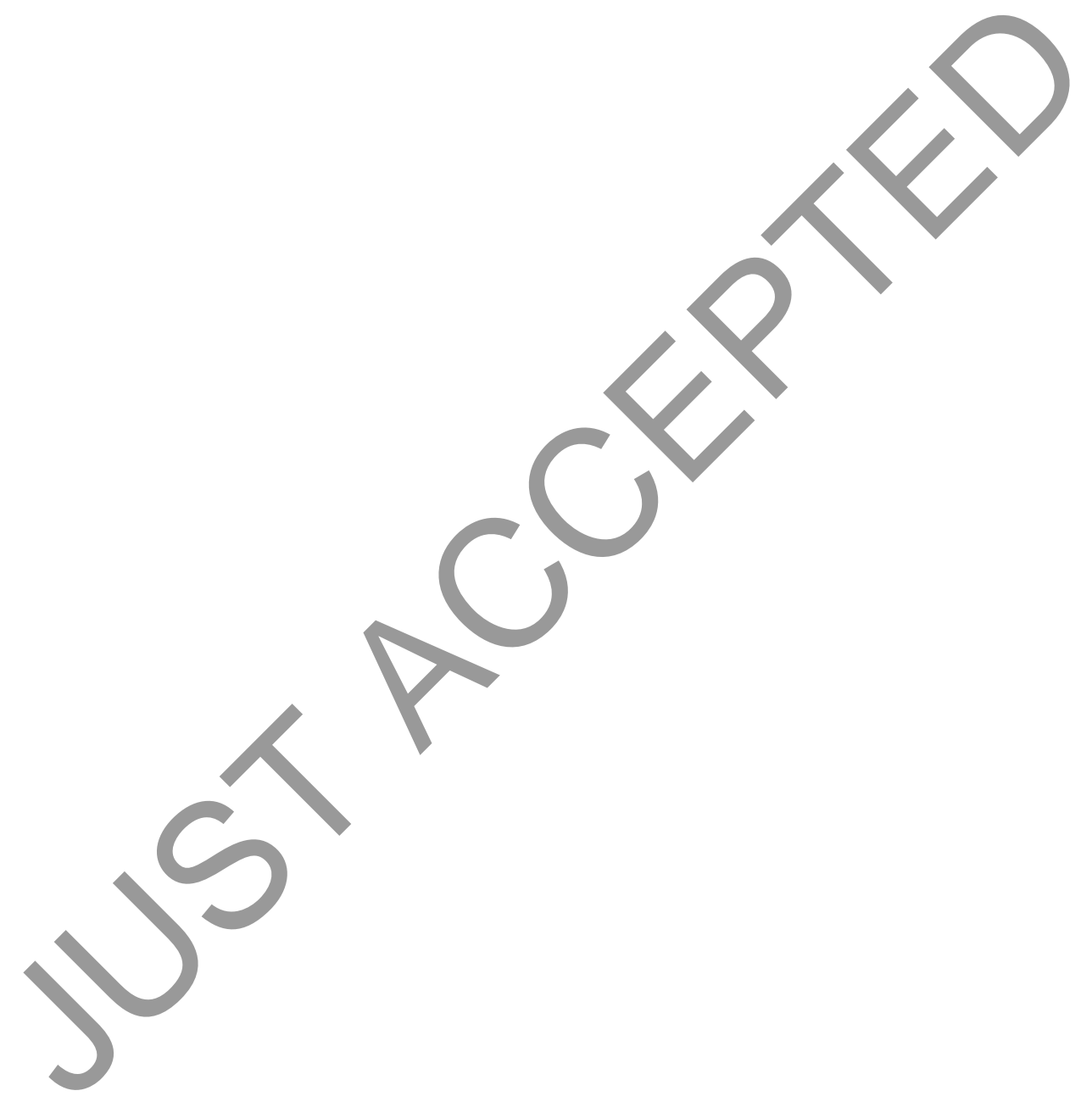




\begin{tabular}{|c|c|c|c|}
\hline Study, year & $\begin{array}{l}\text { Participant } \\
\text { characteristics }\end{array}$ & Exercise measured & Results \\
\hline Fry et al. [94] 2006 & $\begin{array}{l}16 \text { weightlifting-trained } \\
\text { men ( } \mathrm{n}=8 \text { overstained } \\
\text { group, OT; } \\
\mathrm{n}=8 \text { control group, } \mathrm{C})\end{array}$ & $\begin{array}{l}\text { Training: } \\
\text { OT } 10 \times 1 \text { at } 100 \% \\
\text { 1RM daily for } 2 \text { weeks, } \\
\text { C normal training } \\
2 \text { days/week }\end{array}$ & $\begin{array}{l}\text { Significant decreases in } \\
\text { 1-RM strength } \\
(154.4(9.9) \mathrm{kg} \text { post - } \\
\text { vs } 159.3(10.1) \mathrm{kg} \text { pre- } \\
\text { exercise }), 36 \% \text { in mean } \\
\text { power at } 100 \% 1-\mathrm{RM} \\
\text { loads, and muscle } \beta^{2} \text { - } \\
\text { AR density by } 37 \% \text {. } \\
\text { A } 2.4 \text {-fold increased } \\
\text { ratio of AD level to } \beta^{2}- \\
\text { AR density. }\end{array}$ \\
\hline
\end{tabular}

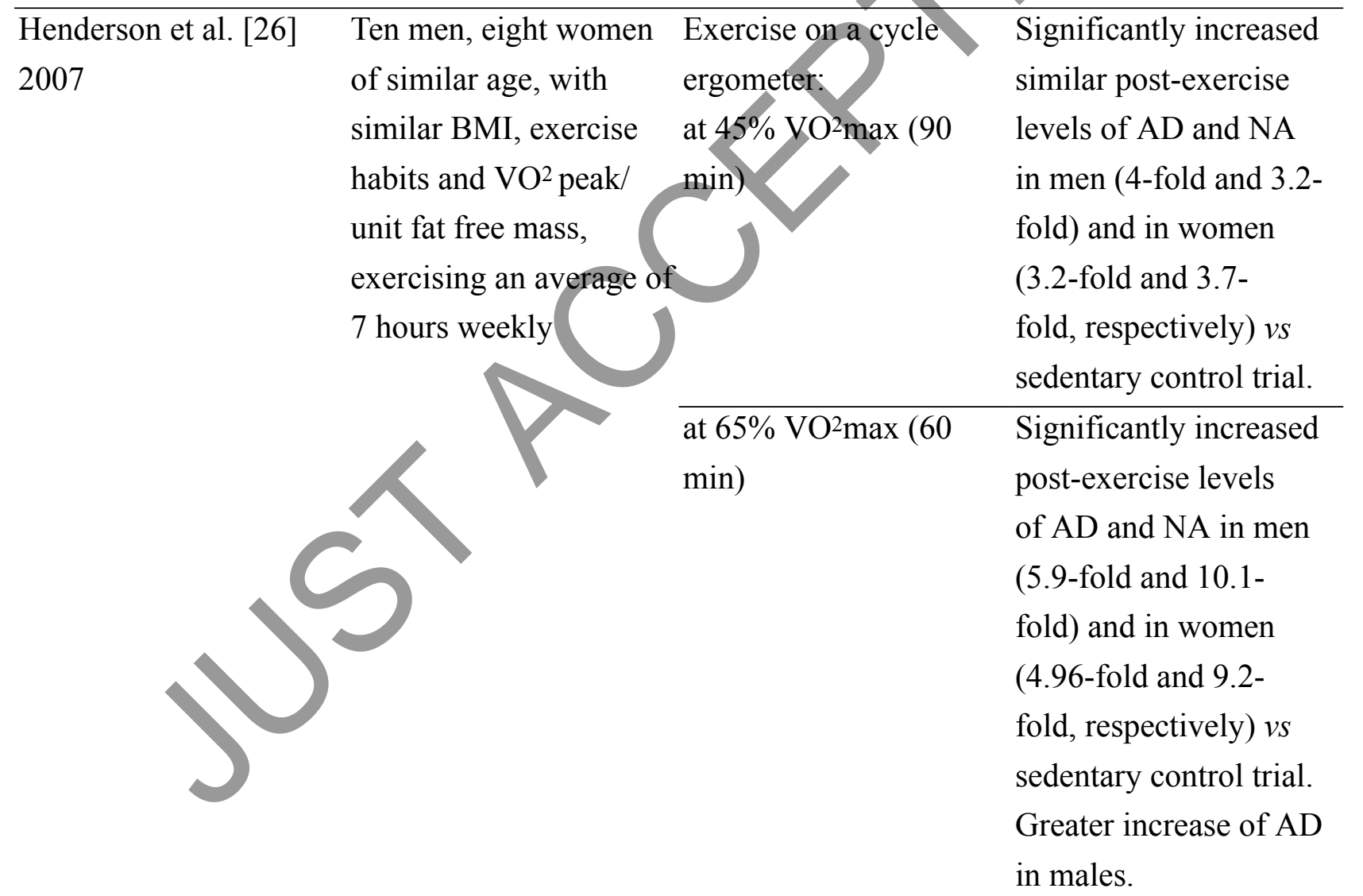

\begin{tabular}{llll}
\hline Jabbour et al. [97] 2011 & 31 adolescent boys & Cycling sprint test six & Significantly \\
& BMI: $18.9 \pm 1.1(\mathrm{n}=11) ;$ & 6-s maximal sprints & increased plasma AD \\
& $24.5 \pm 1.5(\mathrm{n}=11) ;$ & concentrations in \\
& $30.8 \pm 2.3(\mathrm{n}=9)$, matched & response to exercise in \\
& for $\mathrm{VO}^{2}$ max per unit & the lean and overweight \\
& of fat-free mass, age, & groups $v$ measured \\
& height & at rest. Negative
\end{tabular}




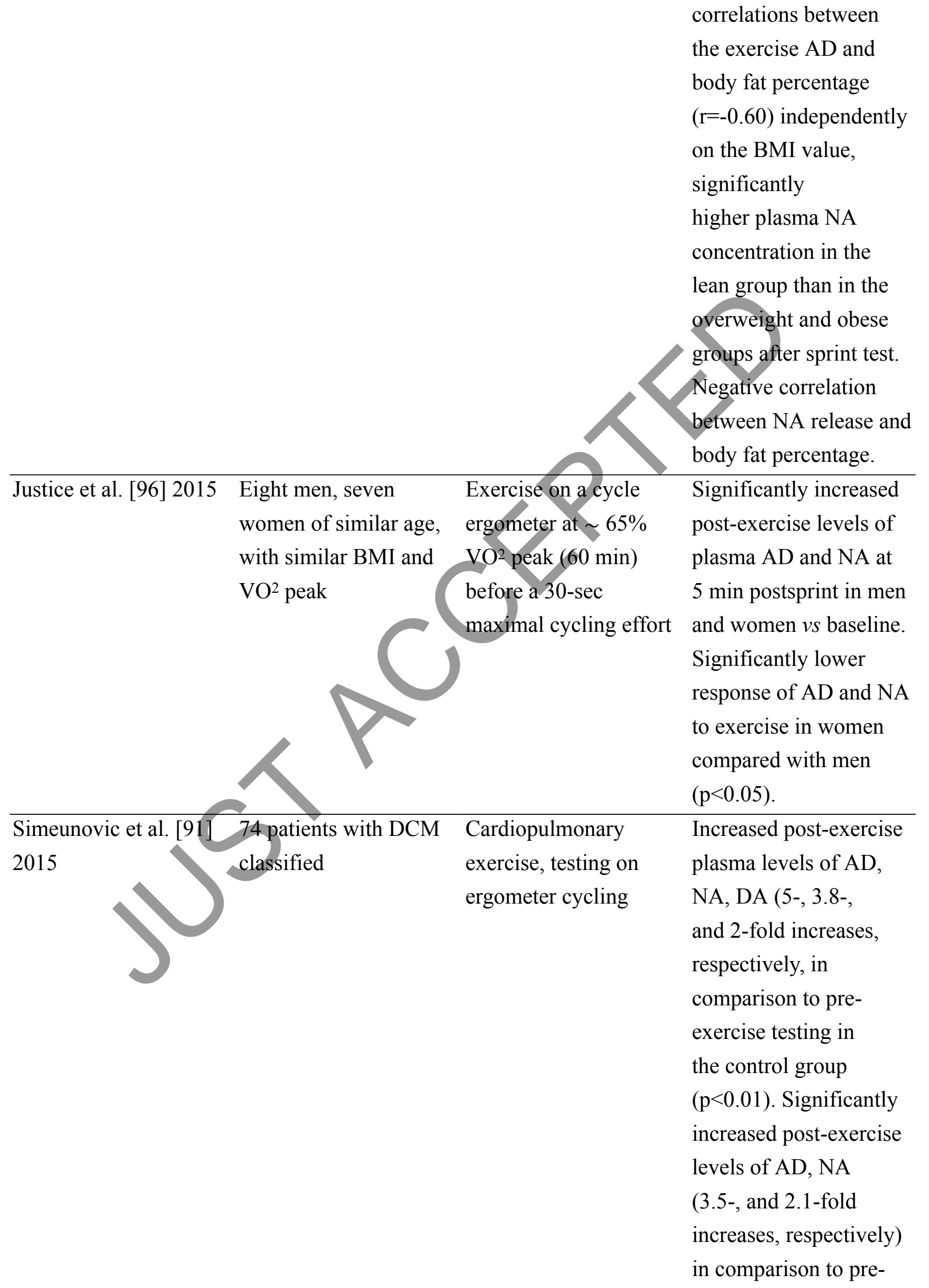


exercise testing in

patients. Additionally,

a significant increase

in CAT, GR and GPX

enzyme levels in the

control group and in

GR enzyme level in

patients with DCM after

exercise test.

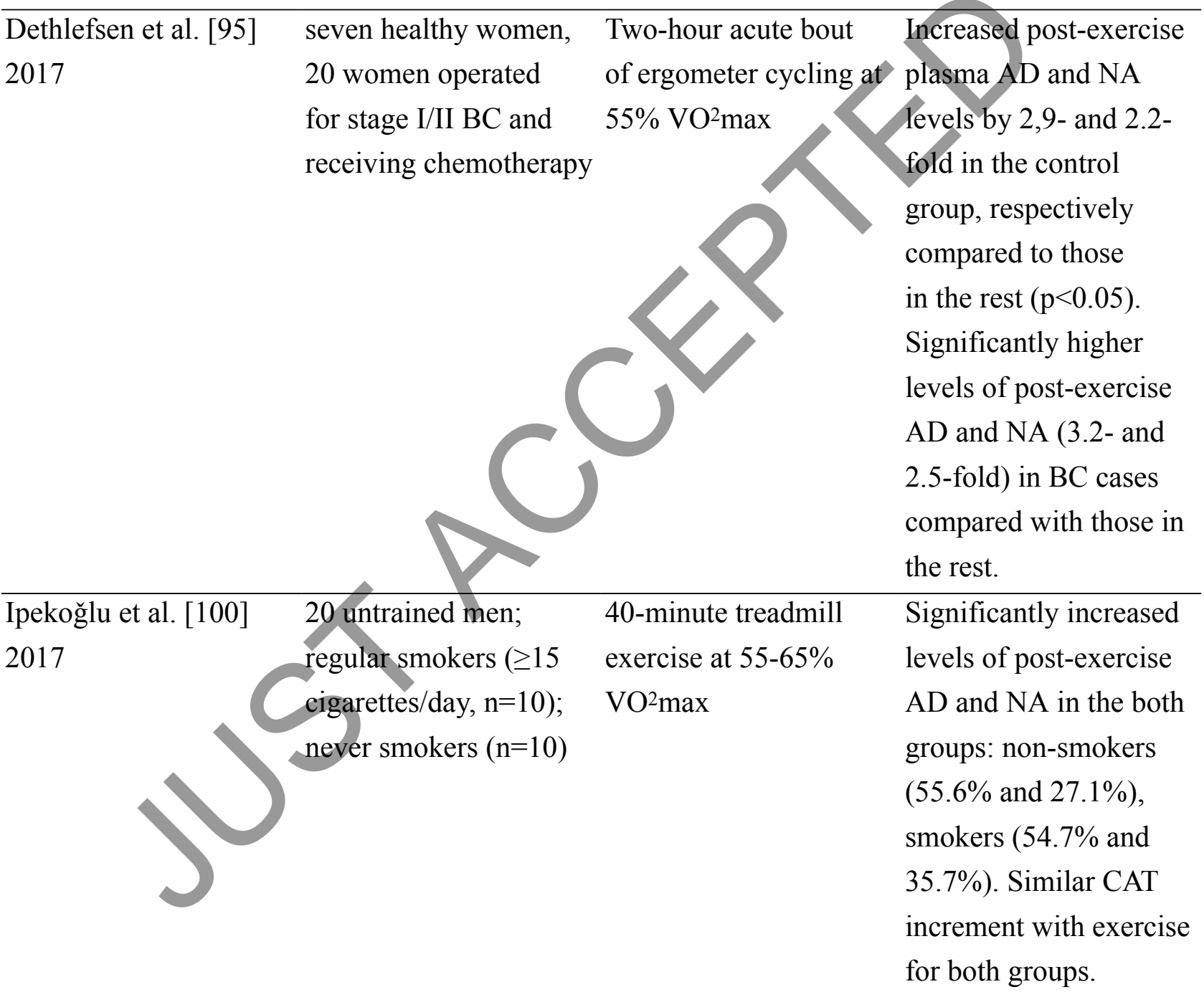

Messan et al. [98] 201786 professional cyclists, Triangular stress test

51

performed

Increased post-exercise

subjects with

on a cycle ergometer,

plasma

bronchospasm, 35

a power increment 50

AD concentrations

subjects without

$\mathrm{W}$ every three minutes

by $7 \# 10^{2 \%}$ in

bronchospasm

until exhaustion.

bronchospasm group

Inability pedaling and by $30 \# 10^{2 \%}$ in the cyclists without 
frequency $90 \mathrm{rev} / \mathrm{min}$ bronchospasm.

determined as fatigue Increased NA

concentrations by

approximately $13 \# 102 \%$

in bronchospasm group

and by $20 \# 10^{2} \%$ in

the cyclists without

an asthma prevalence.

Significantly higher

levels of post-exercise

CAT levels in the

cyclist without

bronchospasm $v s$

those with an asthma

prevalence $(\mathrm{p}<0.001)$.

Wochyński and Sobiech 55 cadets: Three SAGI (looping, Statistically significant

[99] 2017 SAGI-trained $n=41$ (A a gyroscope, an aero increases in AD, NA, group), control group wheel) training sessions DA levels dependent on $\mathrm{n}=14$ (B group) (group A). Group B- the exercise intensity

standard program of after each training

physical education session $v s$ before

during three sessions of the training session.

similar intensity (team Significantly higher

sports, gymnastics, levels of CATs induced

outdoor runs, light in group B than in

athletics) group A in session III.

Danese et al. [21] 201826 amateur runners Half-marathon run Increased post-run

(15 males, 11 females $) \quad(21,1 \mathrm{~km})$ completed

plasma concentrations

engaged in recreational between $75-85 \%$

of $\mathrm{MN}$ and $\mathrm{NMN}$ a

running regimen, $200 \quad \mathrm{VO}^{2} \max$

nearly 3.5- and 7-fold,

$\mathrm{min} /$ week

compared to the pre-run values $(\mathrm{p}<0.0001)$. The

$\mathrm{MN}$ values measured

6 and 24 hours after

run were comparable

to those before the

run. In contrast, the

NMN values at 6 and 
24 hours after the run were significantly 1.46- and 1.33-fold higher $v s$ those preruns, respectively.

\begin{tabular}{|c|c|c|c|}
\hline Shah et al. [90] 2019 & $\begin{array}{l}14 \text { males: men with } \\
\operatorname{HCM}(n=9) \text { control } \\
\text { group }(n=5)\end{array}$ & $\begin{array}{l}\text { MECPET test, cycle } \\
\text { ergometer. Three } \\
\text { minutes warm-up stage } \\
\text { at } 40 \text { watts followed by } \\
\text { eight successive three } \\
\text { minutes stages with } \\
\text { increased workloads by } \\
20 \text { watts per stage }\end{array}$ & $\begin{array}{l}\text { No statistically } \\
\text { significant change in } \\
\text { blood AD and NA } \\
\text { levels from low to } \\
\text { moderate exercise } \\
\text { (below the ventilatory } \\
\text { threshold) intensity, a } \\
\text { rapid increase at higher } \\
\text { intensities. Significant } \\
\text { exponential increase } \\
\text { ( 6-fold) in CATs } \\
\text { levels above ventilatory } \\
\text { threshold } v s \text { the rest } \\
\text { with increasing exercise } \\
\text { stages. }\end{array}$ \\
\hline
\end{tabular}

$1 \mathrm{RM}$ - one repetition maximum; MACPET - maximal effort cardiopulmonary exercise test; DMC - dilated cardiomyopathy; AD - adrenaline; NA - noradrenaline; MN - metanephrine; $\mathrm{NMN}$ - normetanephrine; $\mathrm{VO}^{2} \mathrm{max}$ - maximal oxygen uptake, HCM - hypertrophic cardiomyopathy; BC - breast cancer; SAGI - Special Aerial Gymnastics Instruments; CAT catalase; GR - glutathione reductase; GPX - glutathione peroxidase. 


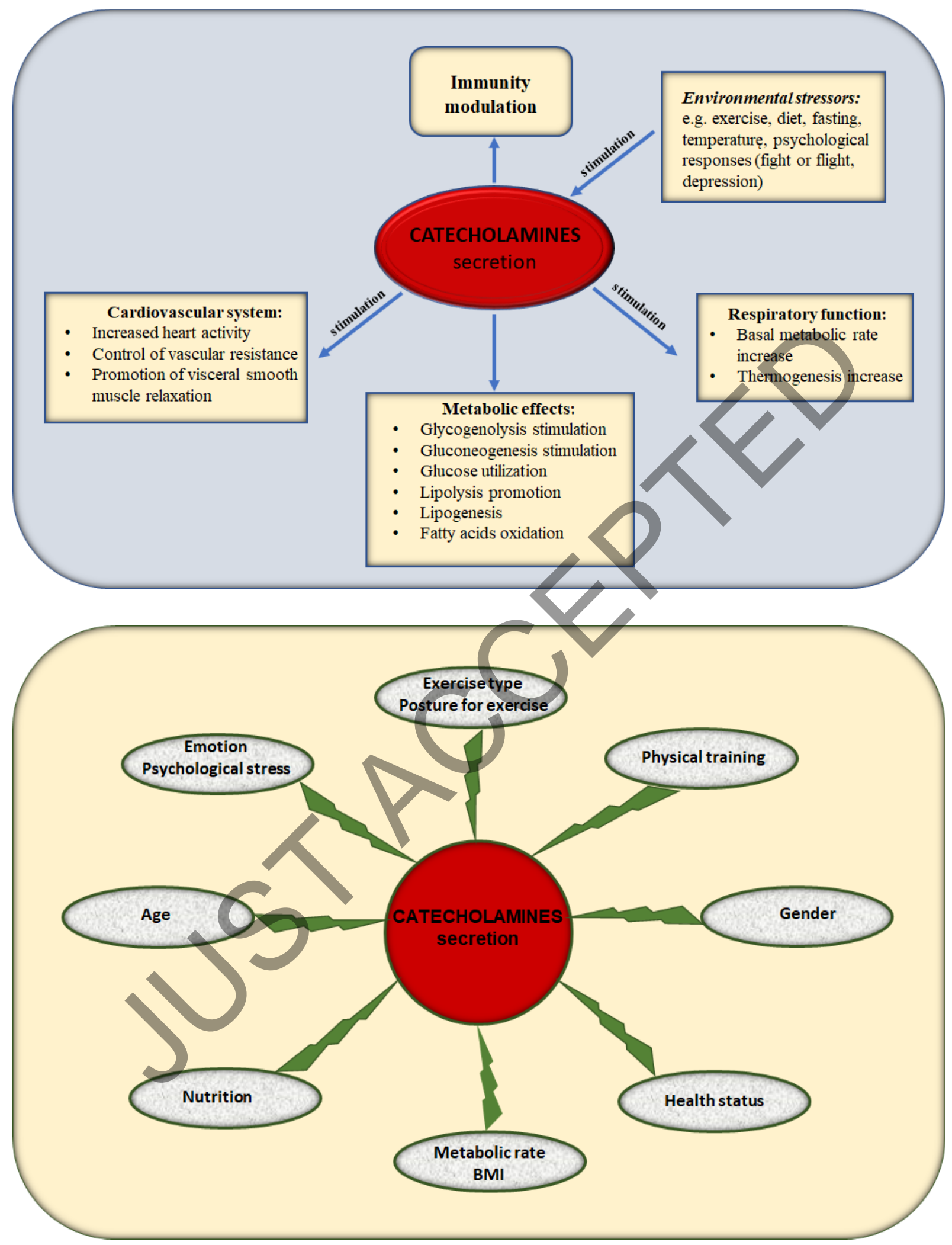




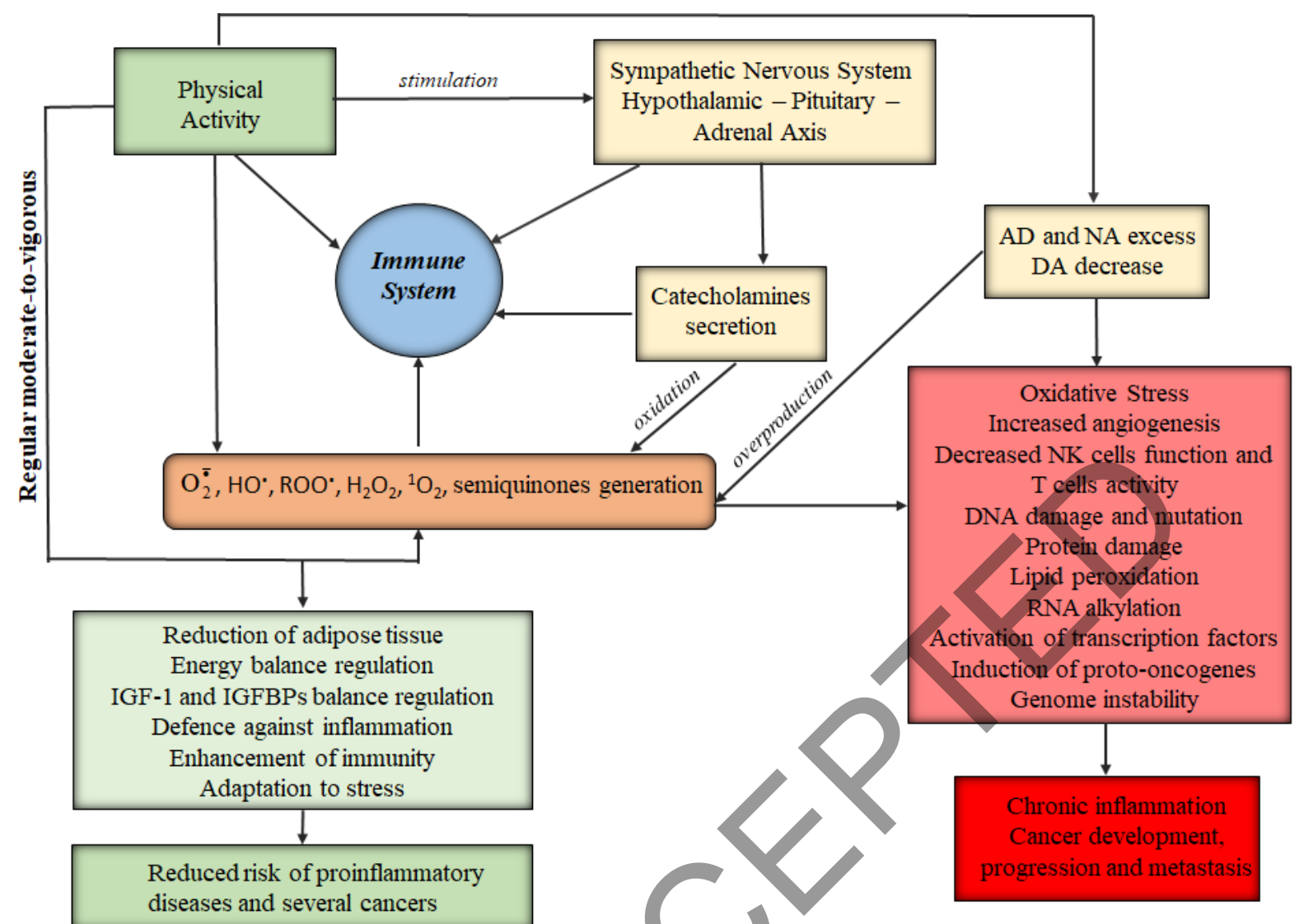



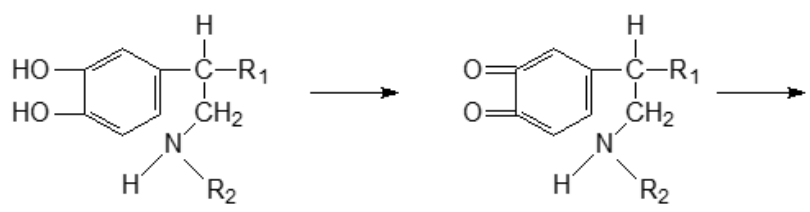

Catecholamine (I)

Catecholamine quinone (II)
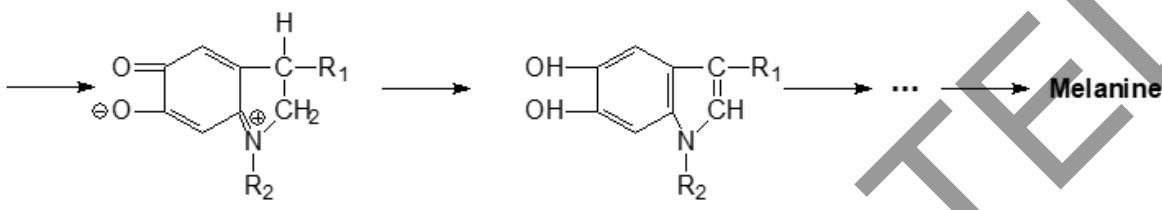

Aminochrome (III)

Indole (IV) 